UNIVERSIDAD POLITÉCNICA DE MADRID

Escuela Técnica Superior de Arquitectura de Madrid

\title{
LA BÓVEDA DE ROSCA COMO PAISAJE CULTURAL-URBANO: ESTUDIO MORFOLÓGICO Y CONSTRUCTIVO A TRAVÉS DE LA CIUDAD
}

Tesis doctoral

Pablo Alejandro Cruz Franco

Arquitecto 


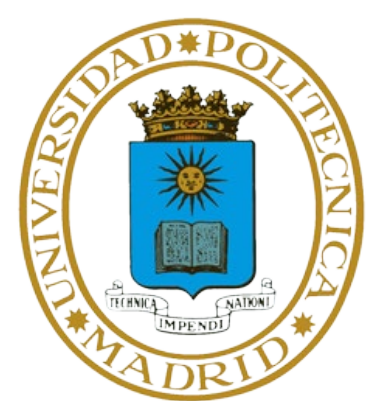

DEPARTAMENTO DE CONSTRUCCIÓN Y TECNOLOGÍA ARQUITECTÓNICAS

Escuela Técnica Superior de Arquitectura de Madrid

LA BÓVEDA DE ROSCA COMO PAISAJE CULTURAL-URBANO: ESTUDIO MORFOLÓGICO Y CONSTRUCTIVO A TRAVÉS DE LA CIUDAD

Tesis doctora

Pablo Alejandro Cruz Franco. Arquitecto

Directora:

Susana Mora Alonso-Muñoyerro. Doctora Arquitecta 


\section{POLITÉCNICA}

Tribunal nombrado por el Sr. Rector Magfco. de la Universidad Politécnica de Madrid, el día................de.............................de 20....

Presidente:

Vocal:

Vocal:

Vocal:

Secretario:

Suplente:

Suplente:

Realizado el acto de defensa y lectura de la Tesis el día..........de... ...de $20 \ldots$

en la ETSI. / Facultad

Calific ación .

EL PRESIDENTE

LOSVOCALES 


\section{GRADECIMIENTOS}

Debo agradecer de manera especial y sincera a la profesora Susana Mora Alonso-Muñoyerro por aceptarme y guiarme en este trabajo a lo largo de los años, primero porque es el fruto de su conocimiento y generosidad pero en segundo lugar y quizás más importante porque sin su cariño nunca se hubiese podido terminar.

También quiero darle las gracias a José Miguel Rueda Muñoz de San Pedro, por escucharme y ayudarme con su intuición y su trabajo, sin importarle ni el tiempo ni el lugar compartiendo su conocimiento y su amor por la arquitectura y la ciudad de Cáceres de forma desinteresada.

AAlbert Meco Alías y Fernando Perianes Díaz, porque me habéis acompañado de forma incansable a través de los años, primero en esa de-construcción ingenua que casi acaba de desastre y más tarde, en ese difícil camino que es la vida siempre habéis estado ahí siendo mis compañeros de viaje.

A Jorge Ramos Sánchez y Rubén Corchado Alegre, sería egoísta pensar que las montañas se escalan solas y gracias a su paciencia se ha podido terminar este trabajo.

\section{A mi familia:}

Mis padres, Máximo y Mercedes, uno tenaz y otro paciente, que por supuesto siempre han estado a mi lado en mis éxitos, pero también y más importante supieron confiar en mi, me ayudaron y me alentaron en mis grandes fracasos, para poder superarlos día a día intentando ser mejor persona.

Mis hermanos, Miguel, firme e incansable, Juan, paciente y estoico, y Jesús, inteligente y generoso, quizás porque siempre he sido el más pequeño nunca ha faltado vuestra ayuda y vuestro apoyo, sabed que sois un ejemplo a seguir día tras día en todo lo que hago.

A ti Adela, que eres un faro en mi vida, primero amiga y luego esposa, eres la razón de todo. Este trabajo que es tuyo y mio es el resultado de aprender de tu constancia y de tu perseverancia y solo tu sabes los obstáculos que nos hemos encontrado. La persona que soy no estaría aquí si no fuese por ti, que con tu alegría y generosidad me has hecho avanzar y mejorar desde hace años, han sido muchas las veces que me he caído pero tu siempre me has tendido tu mano para levantarme y con una sonrisa me has hecho sobreponerme a las adversidades...

Sinceramente gracias..

...Y a ti que vienes y que aunque nunca lo recuerdes nos has acompañado e ilusionado en este viaje tan duro, te dedico este trabajo...

Para ti pequeñita 
1.1. HIPÓTESIS DE PARTIDA

1.2. OBJETIVOS DE LA TESIS

1.3. ALCANCE DE LA TESIS

1.4. JUSTIFICACIÓN DEL TEMA

1.5. ESTADO DEL ARTE

2. LA BÓVEDA DE ROSCA: LA CIUDAD Y LOS EDIFICIOS QUE LA COMPONEN

2.1. LA BÓVEDA DE ROSCA Y SU CONSTRUCCIÓN AL AIRE

2.2. METODOLOGÍA APLICADA

2.3. PATRÓN CONSTRUCTIVO DE LA BÓVEDA DE ROSCA DENTRO DE UNA SELECCIÓN DE EDIFICACIONES EN LA CIUDAD

2.4. EXTRACCIÓN DE CONCLUSIONES PARCIALES: LA MANZANA COMO RESULTADO DE LA UNIÓN DE EDIFICACIONES: "EL AGREGADO URBANO".

3. LA BÓVEDA DE ROSCA: DETECCIÓN Y ANÁLISIS DE CONJUNTOS ESTRUCTURALES. "EL AGREGADO URBANO": 8 CASOS DE ESTUDIO EN LA CIUDAD

3.1. ANÁLISIS DE AGREGADOS URBANOS

3.1.1. AGREGADO URBANO 01: CALLE TIENDAS

3.1.2. AGREGADO URBANO 02: PALACIO DE OVANDO

3.1.3. AGREGADO URBANO 03: PALACIO TOLEDO-MOCTEZUMA

3.1.4. AGREGADO URBANO 04: PALACIO ULLOA

3.1.5. AGREGADO URBANO 05: PALACIO DE LA GENERALA

3.1. AGREGADO URBANO 06: PALACIO DE LA RIVERA

3.7.7. AGREGADO URBANO 7: LIENZO 7 DE LA CERCA 
4. CARACTERIZACIÓN CONSTRUCTIVA DE LA BÓVEDA DE ROSCA A TRAVÉS DE SUS PARTICULARIDADES MORFOLÓGICAS, TIPOLÓGICAS Y CONSTRUCTIVAS

4.1. CARACTERIZACIÓN TIPOLÓGICA Y MORFOLÓGICA

4.2. CARACTERIZACIÓN DE MAMPUESTOS Y MORTEROS

4.3. CARACTERIZACIÓN CONSTRUCTIVA ESTRATOS MURARIOS

5. CARACTERIZACIÓN DE LA BÓVEDA DE ROSCA A TRAVÉS DE SUS PARTICULARIDADES ESTRUCTURALES Y LAS RELACIONES ENTRE EDIFICIOS

5.1. METODOLOGÍA

5.2. CARACTERIZACIÓN Y ANÁLISIS ESTRUCTURAL DEL PALACIO CALLE TIENDAS, 6

5.3. ANÁLISIS ESTRUCTURAL: PALACIO DE OVANDO, VIVIENDAS EN CALLE TIENDAS N 1 Y 3

5.4. ANÁLISIS ESTRUCTURAL DEL PALACIO DE TOLEDO-MOCTEZUMA Y VIVIENDAS EN PLAZA DE MAYOR DE CÁCERES

6. CONCLUSIONES

7. BIBLIOGRAFÍA 


\section{RESUMEN}

La hipótesis de partida de esta tesis es la existencia de un elemento unificador en la Ciudad de Cáceres que condiciona su arquitectura a nivel urbano, constructivo y estructural conformando el "paisaje cultural" de la ciudad. Esta parte esencial de la arquitectura cacereña es la "bóveda de rosca", un particular tipo de bóveda que se ejecuta al aire, esto es sin cimbra.

Con esta hipótesis que inicia la investigación el fin último es la necesidad de valorar esta la bóveda de rosca, desde un punto de vista global, interrelacionando diferentes ámbitos de la arquitectura para poder comprender la ciudad, los edificios y los espacios, desde la óptica de cómo se construyen. Como un elemento con unas peculiaridades históricas, estructurales, morfológicas y estéticas, condiciona una ciudad, convirtiéndose en una pieza clave del Paisaje Cultural que define la identidad de una región, y que sin él, esta arquitectura perdería gran parte de su autenticidad.

Esto da lugar a una búsqueda de valores, tanto históricos, como arquitectónicos como significativos que es el marco conceptual que encuadra el modo de actuación. Así, no solo estamos analizando este sistema constructivo, en realidad estamos definiendo la imagen de la ciudad, estamos viendo como se relacionan los edificios, estamos definiendo un sistema constructivo que no solo es Patrimonio en si mismo sino que además se transforma en imagen urbana. 
El método de análisis propuesto para acometer el estudio es a partir de círculos concéntricos, que sirvan para parametrizar la ciudad buscando elementos en común dentro de las edificaciones. De este modo los diferentes estratos o círculos son capas de información que serán comunes a unos edificios y a otros no.

De acuerdo a esto en nuestra metodología de trabajo respecto a círculos concéntricos (o diferentes escalas de aproximación) se justifica la necesidad de contextualizar este elemento constructivo dentro de la ciudad y plantear su puesta en valor a través de los edificios, es un camino de doble sentido, en el que surgen nuevamente otras necesidades relacionados con el aspecto urbano, así: documentar, controlar, administrar y planificar (las intervenciones), es el resultado inevitable de estudiar un sistema constructivo como imagen urbana de la ciudad (e incluso del territorio) 


\section{INTRODUCCIÓN}

\subsection{HIPÓTESIS DE PARTIDA}

“...en un estado de ánimo similar, el artista inglés Ben Nicholson (1894-1982) se enfrascó en el problema de su elección. Mientras Mondrian exploraba las relaciones de los colores elementales, Nicholson se concentró en las formas simples como el circulo y el rectángulo, que solia esculpir en tablas blancas dando a cada una de ellas una profundidad ligeramente distinta.

...es fácil adivinar el estado de ánimo en el que un individuo puede quedar completamente embargado por el misterioso problema de relacionar unas cuantas formas y tonalidades hasta darles una apariencia acertada.

Es muy posible que un cuadro que no contenga más que dos rectángulos pueda causarle a su autor más inquietudes que las que le produjo a un artista del pasado pintar una madona. Este

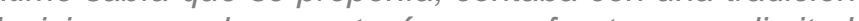

El pintor abstracto, con sus dos rectángulos, se halla en una posición menos envidiable. Puede trasladarlos de lugar por toda la tela, intentar un número infinito de posibilidades y no saber nunca cuando y donde detenerse."

E.H. GOMBRICH
La hipótesis de partida de esta tesis es la existencia de un elemento unificador en la Ciudad de Cáceres que condiciona su arquitectura a nivel urbano, constructivo y estructural conformando el "paisaje cultural" de la ciudad. Esta parte esencial de la arquitectura cacereña es la "bóveda de rosca".

El fin último es la necesidad de valorar esta tipología, desde un punto de vista global $^{1}$, interrelacionando diferentes ámbitos de la arquitectura para poder comprender la ciudad, los edificios y los espacios, desde la óptica de cómo se construyen. Como un elemento con unas peculiaridades históricas, estructurales, morfológicas y estéticas, condiciona una ciudad ${ }^{2}$, convirtiéndose en una pieza clave del Paisaje Cultural que define la identidad de una región, y que sin él, esta arquitectura perdería gran parte de su autenticidad ${ }^{3}$.

1 "Todas las ciudades del mundo al ser el resultado de un proceso de desarrollo más o menos espontáneo, o de un proyecto deliberado, son la expresión material de la diversidad de las sociedades a lo largo de su historia". (...)

Carta Internacional para la Conservación de las Ciudades Históricas. Toledo 1986

2 "La humanidad ha de aspirar a transmitir el patrimonio monumental común con toda la riqueza de su autenticidad". (...)

Carta Internacional sobre la Conservación y la Restauración Monumentos y Sitios. Venecia, 1964 


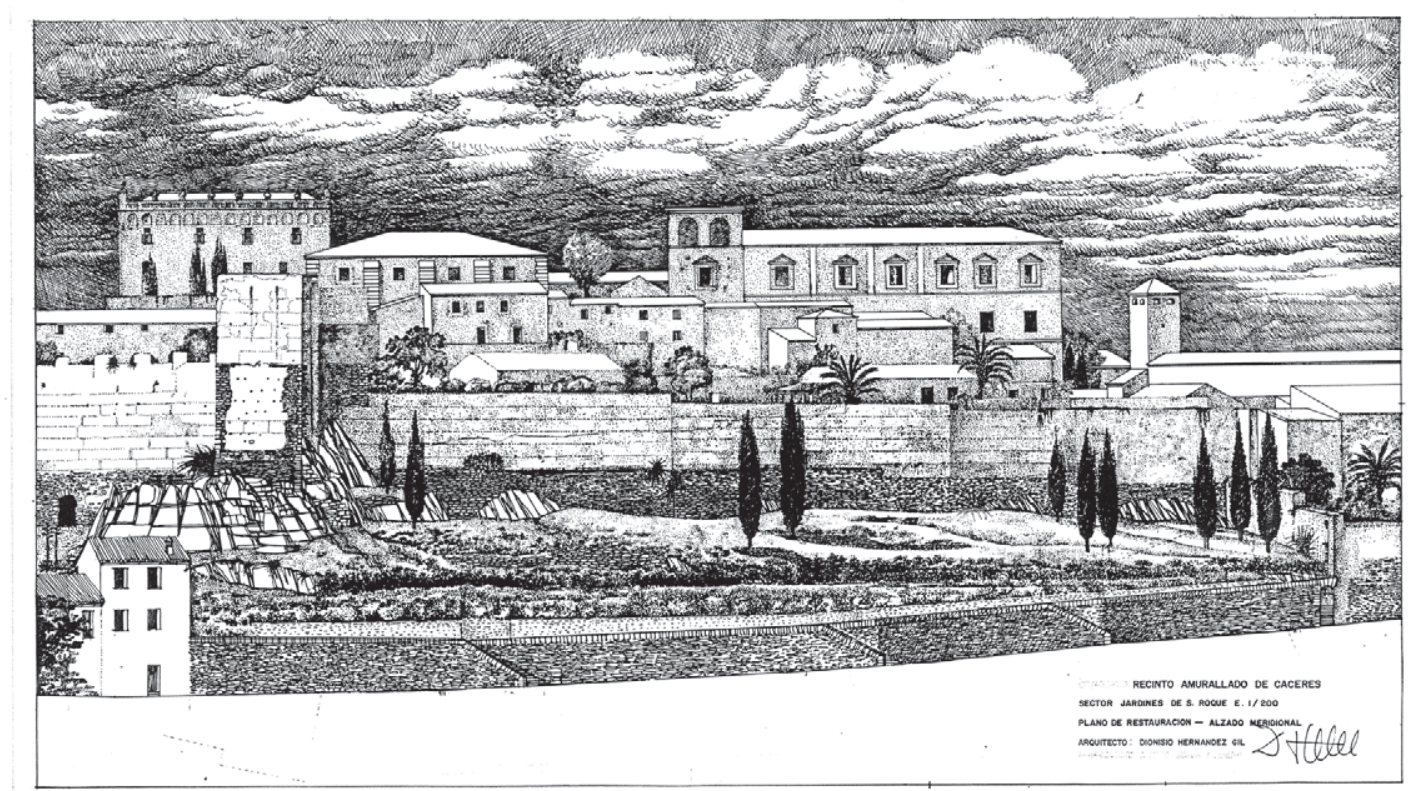

Figura1. Recinto amurallado de Cáceres. Sector jardines de San Roque. Plano de restauración Alzado meridional. Arquitecto: Dionisio Hernández Gil

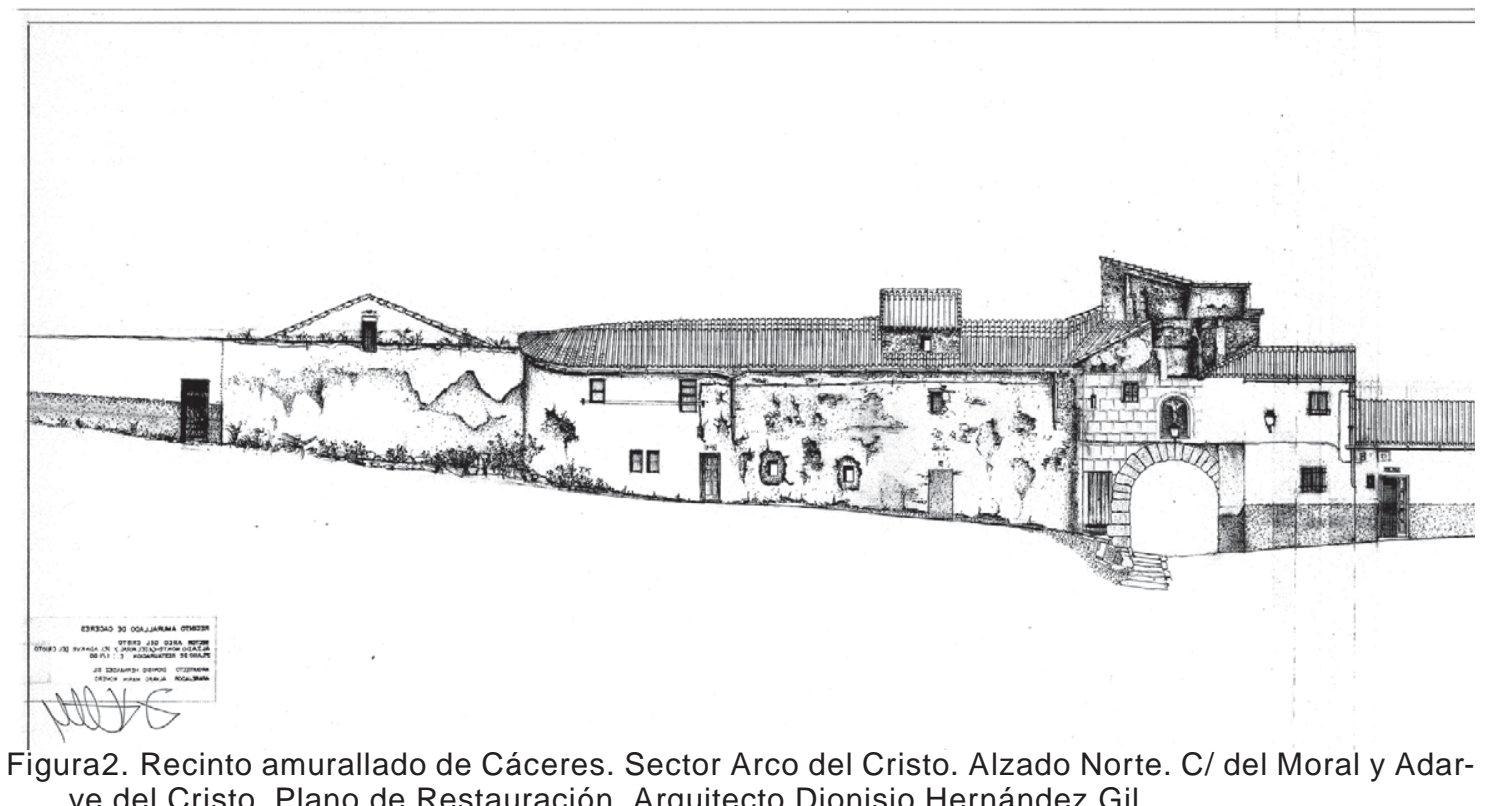

ve del Cristo. Plano de Restauración. Arquitecto Dionisio Hernández Gi
Para poder desarrollar la hipótesis Cáceres se transforma en un campo de investigación ${ }^{4}$. Cabe señalar como históricamente esta ciudad ha mantenido una coherencia constructiva hasta la llegada de la época moderna, donde las técnicas tradicionales comienzan a ser sustituidas por los nuevos materiales acero, hormigón,...) estandarizándose las formas de construir. Pero a diferencia de en otros puntos de nuestra geografía, esta ciudad tiene una singularidad que la hace única y digna de considerarse ciudad patrimonio de la humanidad, un casco histórico prácticamente inalterado, donde la tradición constructiva del siglo XV se repite a lo largo de los edificios de diferentes épocas creando una telaraña de construcciones que forman un conjunto único en el mundo.

El planteamiento de la investigación es a través de la escala como si de un proyecto de arquitectura se tratase. De este modo, se puede hacer entrar en valo a la bóveda de rosca como un elemento constructivo indispensable para el paisaje cultural-urbano, así el desarrollo de la hipótesis se apoya en tres objetivos:

\section{OBJETIVO 01: Estudio de la bóveda de rosca a través de la ciudad y los} edificios que la componen.

1. Inventariar de una forma concisa y rigurosa, las diferentes zonas de la ciudad. Este inventario se realiza para generar una base conocimiento que estructure y cimente el resto de la investigación. Es una herramienta previa y necesaria para continuar más tarde con estudios pormenorizados de las

4 Es necesaria la siguiente cita para contextualizar este concepto: "La autenticidad de un elemento o del monumento en su conjunto no se basa tanto en la "originalidad temporal" de la materia o de su naturaleza, como en que sea capaz de autenticar- "de acreditar de ciertos"-Ios valores del monumento: de documentar los atributos espaciales, mecánicos y formales inherentes a los sistemas constructivos y los elementos ornamentales originales( o, incluso, en ocasiones, las señales, las huellas que la historia y los avatares han dejado en unos y otros), y de permitir la funcionalidad y la significación- estética y emblemática- que unen el monumento a la colectividad." GONZÁLEZ MORENO-NAVARRO, A. 2000. La restauración objetiva: método SCCM de restauración monumental. Memoria SPAL 1993-1998, Barcelona. P. 22 
edificaciones. Este trabajo de campo y gabinete se resume en un sistema de fichas que organizan la documentación relevante para el estudio de las edificaciones.

2. Estudio, análisis y extracción de conclusiones de los datos obtenidos en el punto 1 (microfichas). Localización de una trama: obtención de una primera visión general de la repercusión de la "bóveda de rosca" dentro de la trama urbana y de los edificios de la ciudad. Selección de edificios dentro de esta primera clasificación, por sus atributos artísticos, estructurales, constructivos, tipológicos, morfológicos... para un segundo estudio más detallado

3. Estudio y análisis pormenorizado de edificios en los que se detecten datos relevantes para la investigación. Para segundo este segundo inventario se utilizará también un sistema de fichas que permita organizar la investigación de forma sistemática y científica.

4. Estudio de la morfología de la ciudad a través de las conclusiones obtenidas en las fichas y microfichas, para tener una visión precisa de su contribución. Para hacernos cargo de la importancia de este sistema ha de considerarse desde el origen del propio proyecto. $Y$ será aquí, en este punto cuando estemos en condiciones de conocer el impacto que este sistema tiene sobre la forma y por extensión sobre la ciudad. 
Objetivo 02: Caracterización de la bóveda de rosca a través de sus particularidades morfológicas, tipológicas y constructivas.

1. Localización e inventariado de las diferentes tipologías de bóvedas de rosca a través de casos concretos, procediendo a su comparación y extracción de conclusiones a partir de los textos de August Choisy

2. Análisis, estudio y extracción de conclusiones de las diferentes tipologías de bóvedas localizadas analizando su proceso de ejecución en casos concretos.

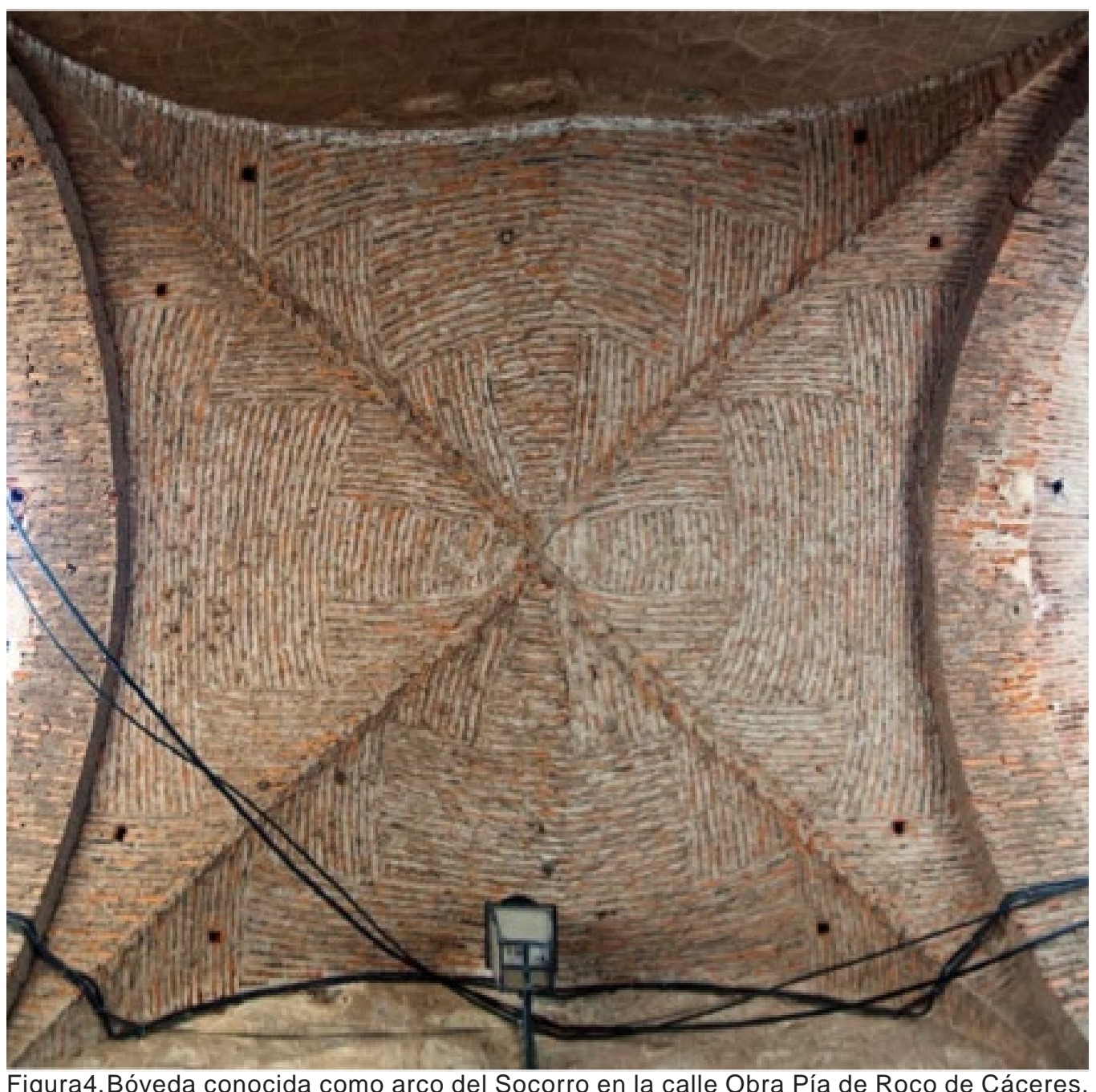

3. Comparación y extracción de conclusiones de los datos obtenidos con los textos de August Choisy

4. Comparación y extracción de conclusiones de los datos obtenidos con los textos de August Choisy

5. Análisis, estudio y extracción de conclusiones de su composición a través de casos concretos en los que ha sido posible la obtención de fábricas reales para poder parametrizar y acotar el elemento constructivo.

6. Análisis, estudio y extracción de conclusiones de paramentos verticales en los casos de estudio con el objeto de parametrizar los apoyos del elemento constructivo. 


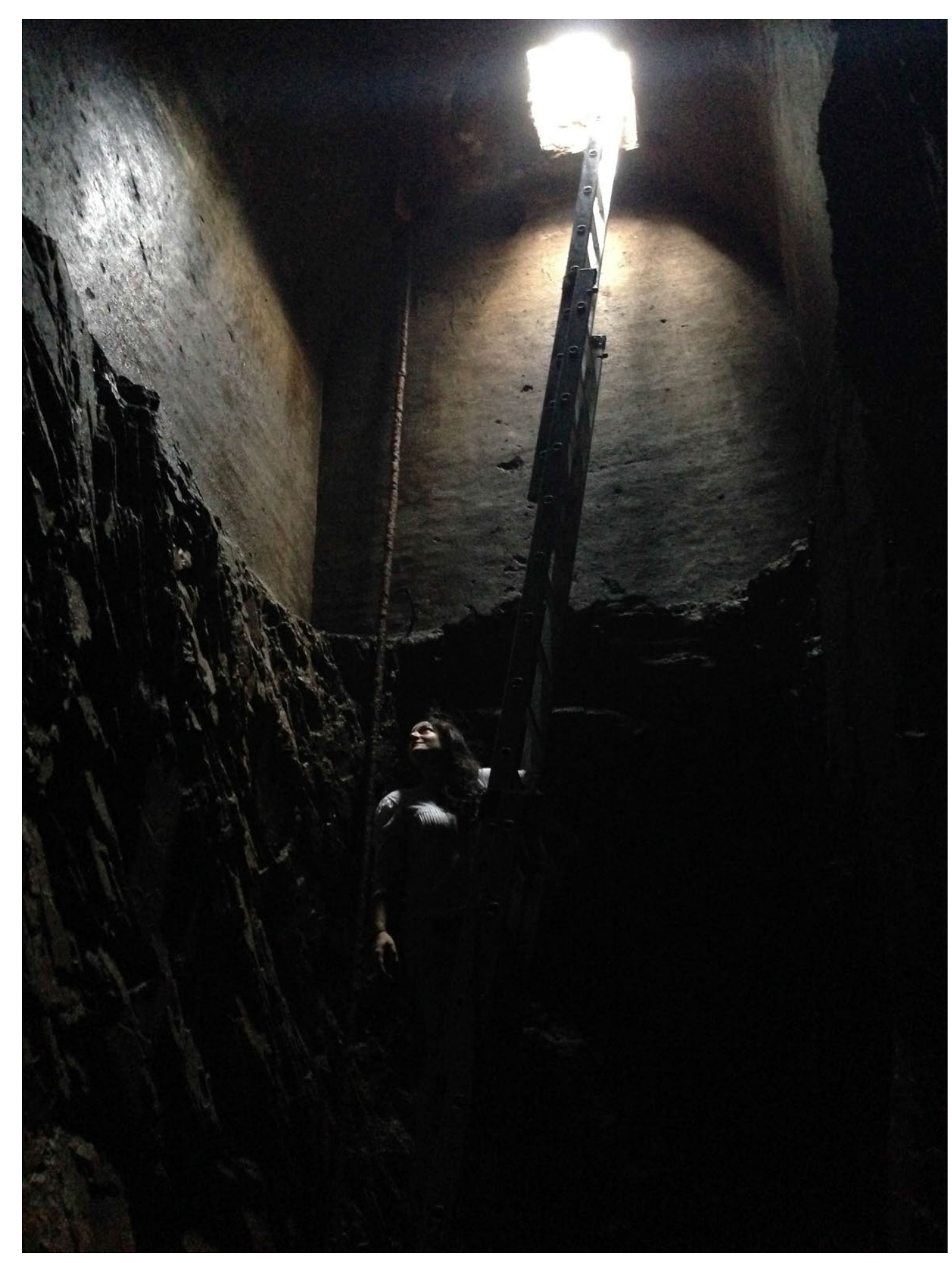

Figura5. Imagen del aljibe situado en Palacio Tiendas $n^{0}$ 6. Boveda de cañón seguido ejecutada a rosca. Trabajos de inspección. Obras de
quitectos. Imagen del autor julio de 2015
OBJETIVO 03: caracterización de la bóveda de rosca a partir de sus particularidades estructurales y sus relaciones con los edificios.

1. Buscar indicadores, parámetros y criterios en intervenciones ya realizadas en edificios ejecutados con bóvedas de rosca, o elementos tradicionales, que nos permitan compararlos, estudiarlos y clasificarlos, como fuente documental.

2. Estudio de las diferentes configuraciones de los edificios analizados que arrojen información de como es la transmisión de cargas dentro de las edificaciones para poder proponer un protocolo de intervención tanto en elementos singulares como en conjuntos de estos que nos permita acercarnos a estos edificios desde el conocimiento y el deseo de que perdure su esencia.

3. Estudio de las posibles relaciones de los edificios analizados con sus edificaciones vecinas que pongan de manifiesto el comportamiento solidario de estas tipologías edificatorias y las implicaciones que esto tiene. 


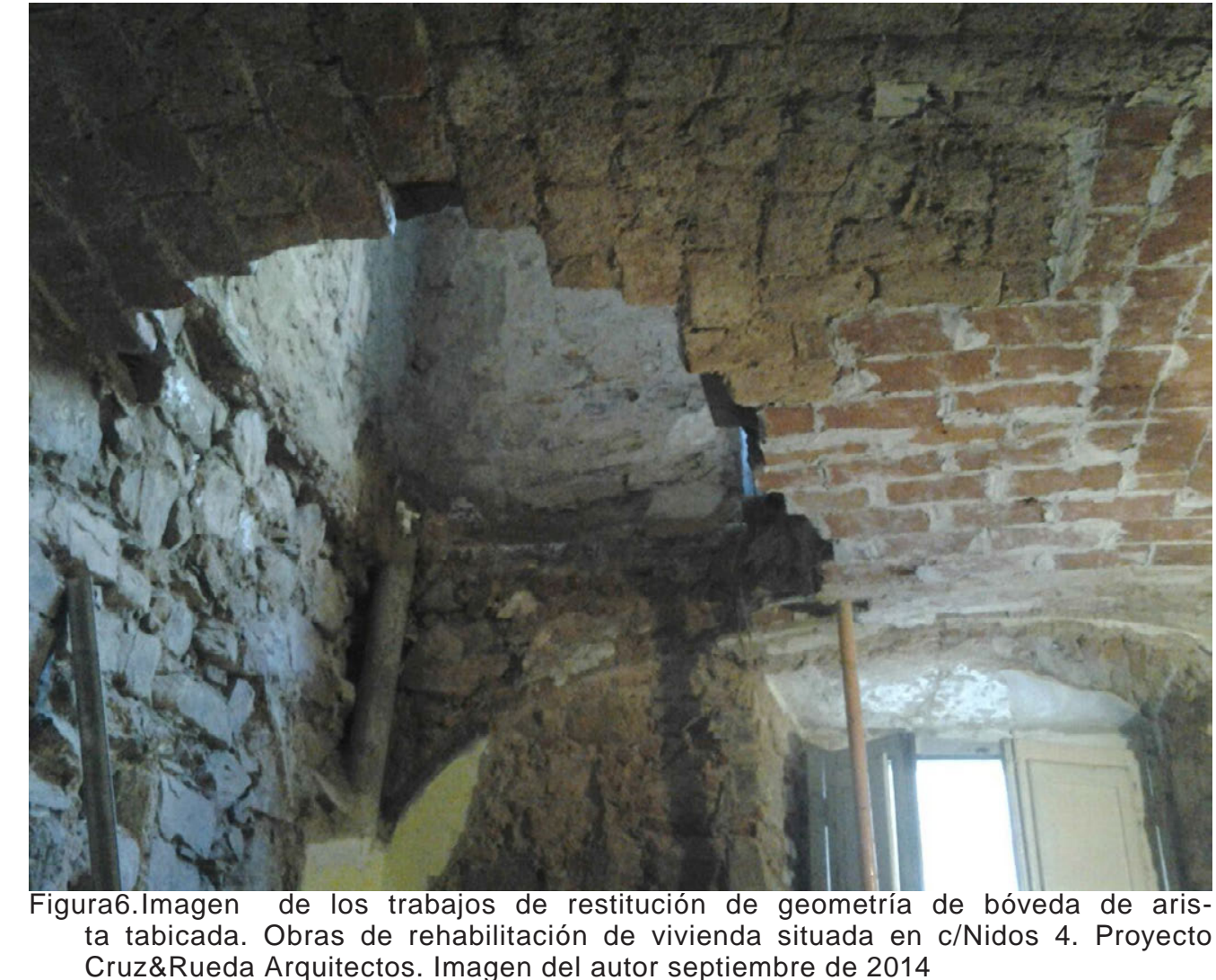

ta tabicada. Obras de rehabilitacion de vivienda situada en

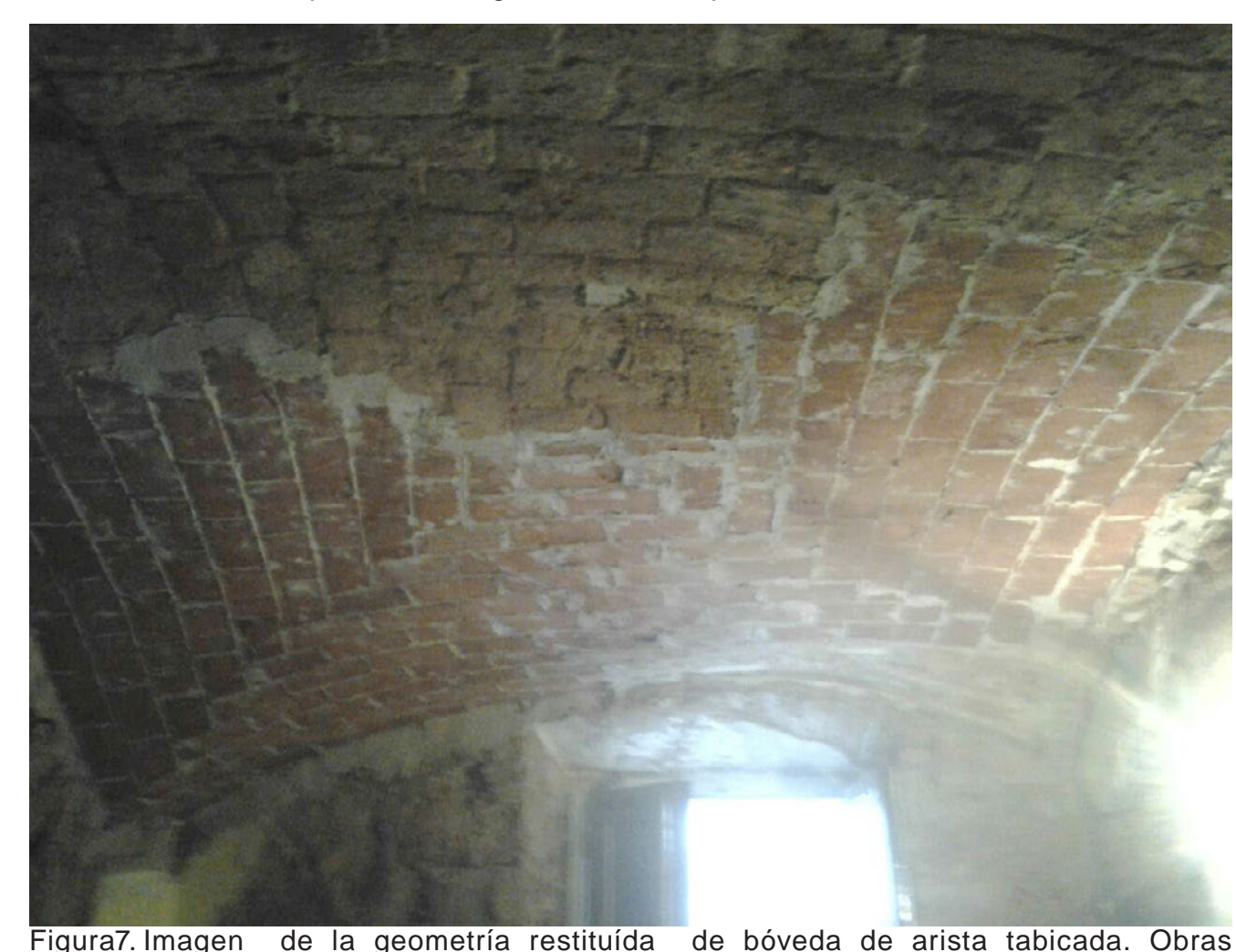

de rehabilitación de vivienda situada en c/Nidos 4. Proyecto Cruz\&Rueda Arquitectos. Imagen del autor septiembre de 2014

\subsection{ALCANCE DE LA TESIS}

El ámbito de esta tesis es dual, por un lado se inicia con la necesidad de analizar y caracterizar un sistema constructivo a través de sus valores documentales, sus valores arquitectónicos y sus valores significativos y comprobar que forma parte de nuestro paisaje cultural, a través de las relaciones entre "la forma", "la construcción" y "la estructura". Pero a medida que la investigación avanza y el conocimiento de este sistema se amplia, surge la necesidad de ampliar la investigación incorporando otra dimensión que enriquezca el análisis, así se incorpora el análisis de las edificaciones como conjunto al entender que es necesaria una lectura global de los casos de estudio.

Dependiendo del edificio que estudiemos, cobra mayor o menor importancia según el autor de la obra. Pero lo cierto es que en muchas ocasiones, estos elementos se conjugan de forma ejemplar y el espacio queda caracterizado dando lugar a una arquitectura que sólo se puede entender si comprendemos el conjunto.

La "bóveda de rosca" en Extremadura y en este caso concreto, en la Ciudad de Cáceres, es un elemento que se repite y se repite a lo largo del tiempo; que aparece indistintamente en las diferentes tipologías y crea una trama peculiar y única, que responde a esta forma de construir, condicionando la ciudad en sus diferentes escalas: desde la casa más humilde al palacio más bello pasando por el coro de una iglesia o escondidas en los numerosos aljibes que abastecen la ciudad.

Y es esta repetición a lo largo de la ciudad de Cáceres (en este caso concreto, porque en realidad es extrapolable a Extremadura) en todas sus escalas y a lo largo del tiempo, sobre la que se apoya este trabajo, como ya veremos. Es la premisa, el pistoletazo de salida, que motiva la búsqueda de los "valores significativos", "valores históricos" y "valores arquitectónicos" para poder comprender este elemento, que lejos de las arquitecturas más monumentales y grandilocuentes, es 

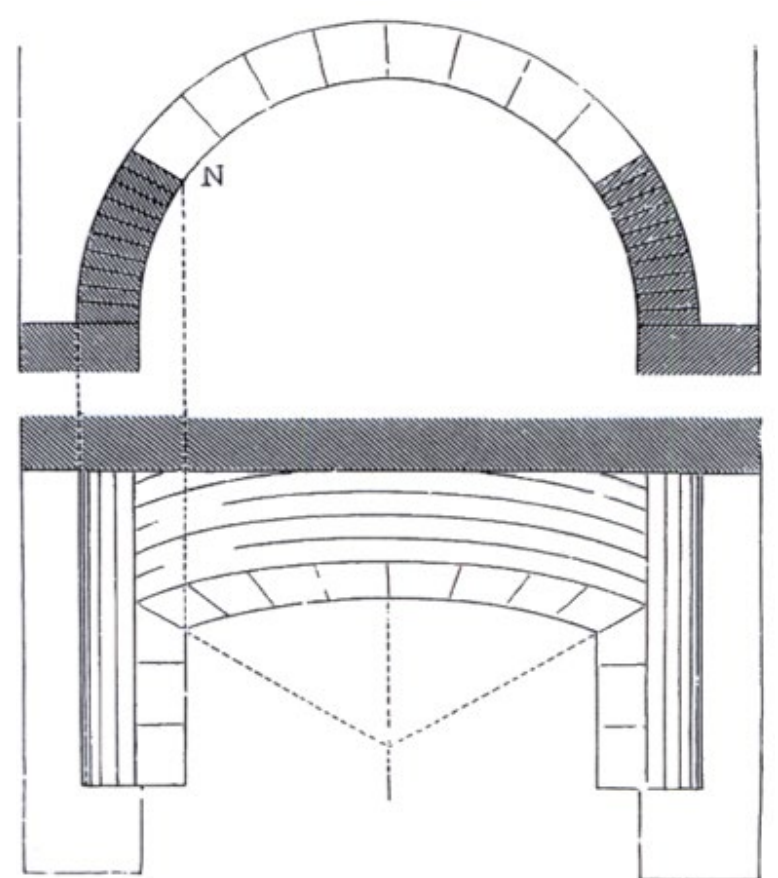

Figura8.CHOISY, Auguste, "El arte de construir en Bizancio", CEHOPU, CEDEX, Ins 36. Construccín mixta de bóveda de cañón a base de hojas e hiladas."
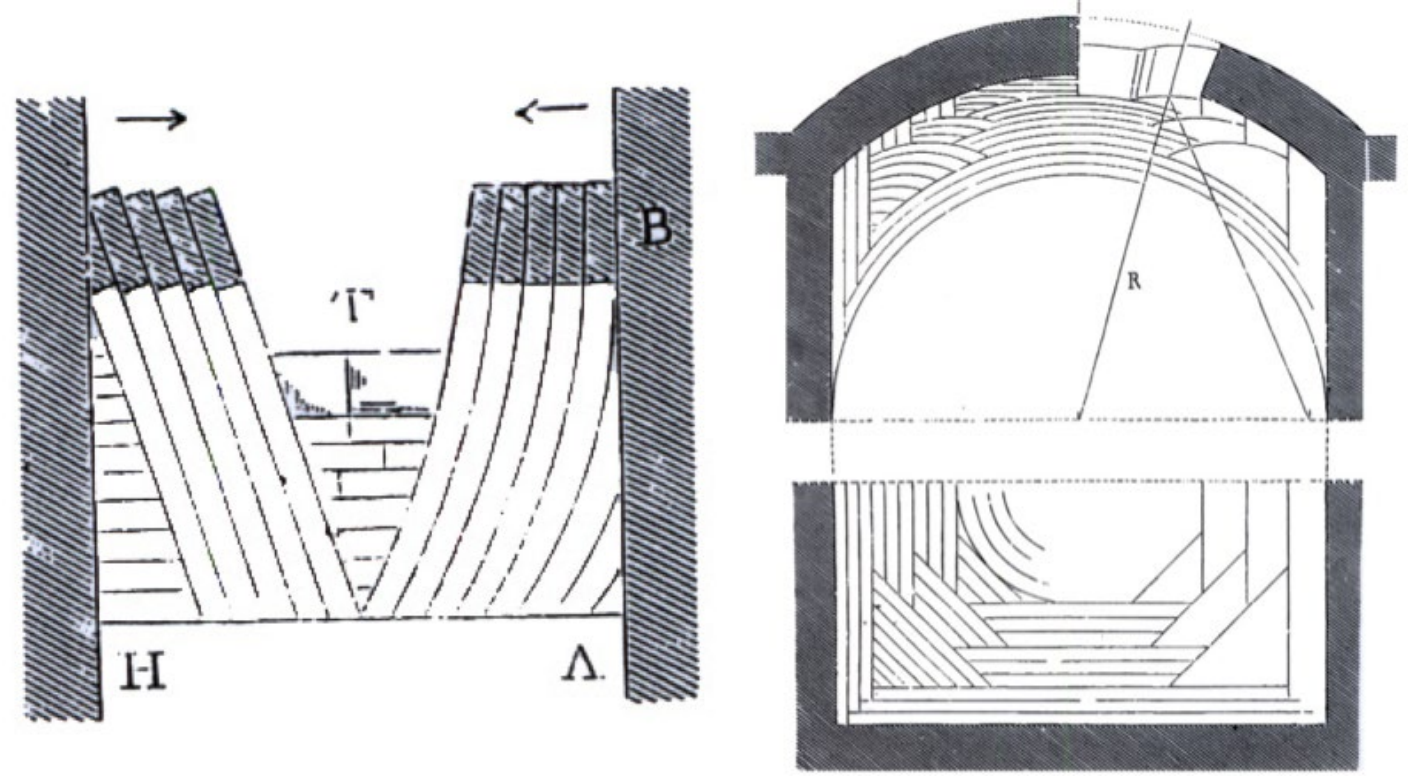

Figura9.CHOISY, Auguste, "EI arte de
construir en Bizancio", CEHOPU, CEDEX, construir en Bizancio", CEHOPU, CEDEX,
Instituto Juan de Herrera, 1997. P 38 . "Figura 40. Bóveda de hojas construída desde los muros de cabeza hacia el centro( arco
de constantino)." Figura11. CHOISY, Auguste, "El arte de construir en Bizancio", CEHOPU, CEDEX,
Instituto Juan de Herrera, 1997. P 106 . " Figura 121. Bóveda esférica en lab. se alternan hojas paralelas a los planos diagonales y los formeros." al fin y al cabo, la expresión material de la historia y de la tradición arquitectónica de un pueblo ${ }^{5}$

Para analizarlas y comprender este trabajo es necesario racionalizar nuestro pensamiento: todo tiene una explicación, y comprender un problema pasa por analizarlo de forma global. La arquitectura que hoy vivimos es el resultado de una historia, Es difícil entrar a valorar la importancia de las cosas. Mientras que unos se sienten embargados al contemplar a Las señoritas de Avignon, para otros, estas no son más que líneas que rompen con toda la pintura que se había visto hasta ese momento, con el realismo, y no le encuentran sentido.

Al contemplar la Villa Saboya de Le Corbusier, no se puede comprender su importancia si no la enmarcamos dentro de un contexto social y político, dentro de un mundo en proceso de cambio que necesitaba ideas nuevas.

Todo lo que nos rodea, tiene una historia, procede de algún lugar, tiene una identidad, un significado... con este punto de partida para estudiarlas y

\section{$5 \quad(\ldots)$}

Artículo 2. Los valores a conservar son el carácter histórico de la población o del área urbana todos aquellos elementos materiales y espirituales que determinan su imagen, especialmente

La forma urbana definida por la trama y el parcelario

La relación entre los diversos espacios urbanos, edificios, espacios verdes y libres;

La forma y el aspecto de los edificios (interior y exterior), definidos a través de su estructura, volumen, estilo, escala, materiales, color y decoración

Las relaciones entre población o área urbana y su entorno, bien sea natural o creado por el hombre; Las diversas funciones adquiridas por la población o el área urbana en el curso de la historia.

Cualquier amenaza a estos valores comprometería la autenticidad de la población o área urban histórica.

Carta Internacional para la Conservación de Poblaciones y Áreas Urbanas Históricas (1987). Adoptada por ICOMOS en octubre de 1987 


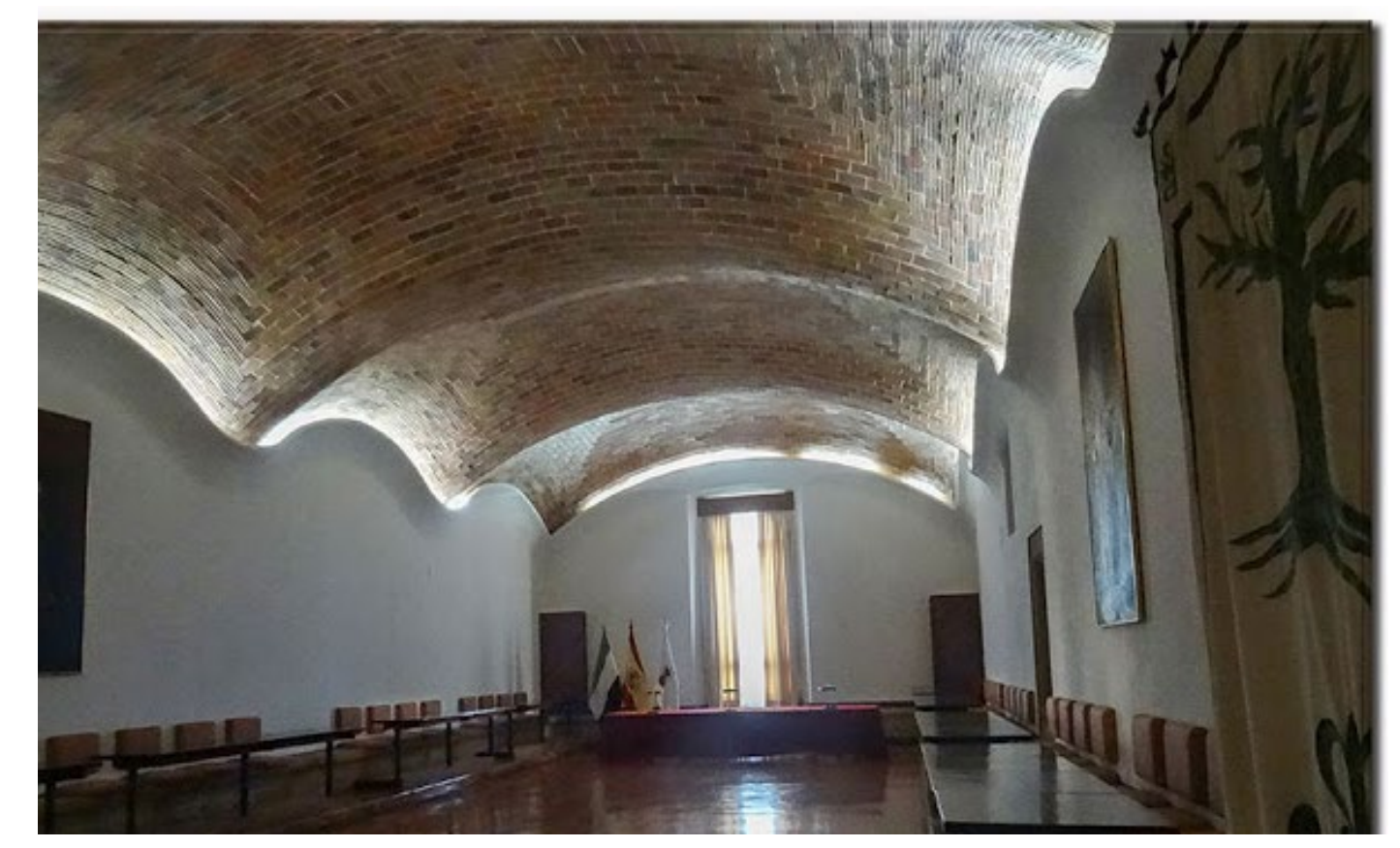

Figura12. Imagen de la reintrepación de las bóvedas del refectorio del convento de San Bento de Alcántara obra del arquitecto Dionisio Hernández Gil. Imagen de Teólfilo Amores.

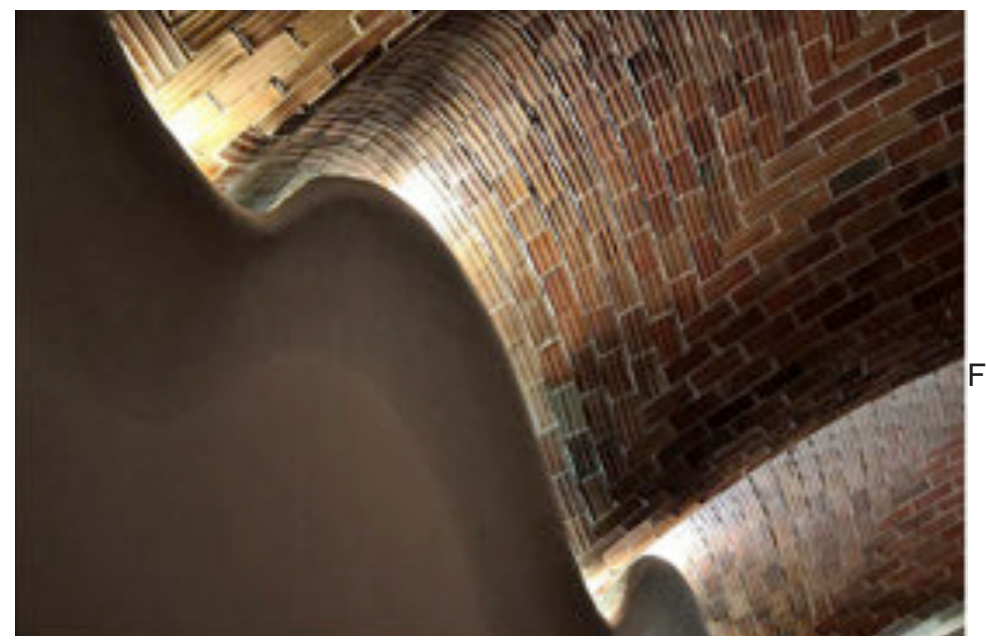

gura13. Detalle de rein terpretación de las bóvedas San Benito de Alcántara obra del arquitecto Dionisio Hernández Gil. Autor de la imagen desconocido.
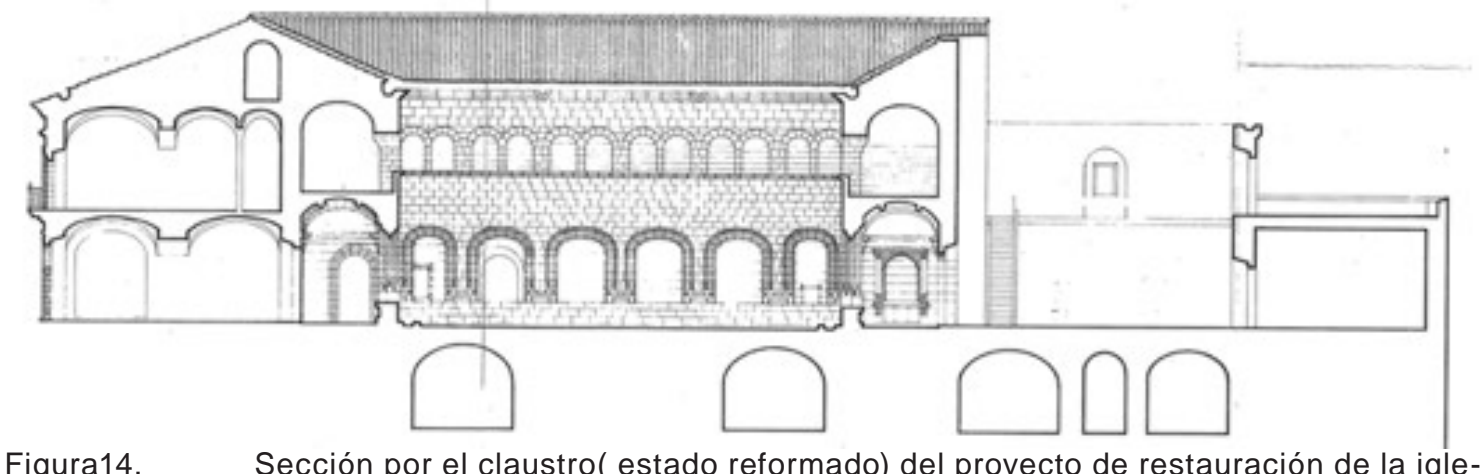

Figura14. Sección por el claustro( estado reformado) del proyecto de restauración de la igleCáceres). Arquitecto: Dionisio Hernández Gil. Planos cedidos por Damian Arroyo Ramos, director de ejecución de las obras. mirar la ciudad y con la ayuda de distintos autores ${ }^{6}$ que movidos por el amor a la arquitectura han escrito ya sobre ellas, vemos que tienen una identidad propia, y una característica fundamental, se ejecutan al aire, sin ayuda de cimbra, hecho que les confiere unos atributos tanto morfológicos, como estéticos, como estructurales, que como veremos más adelante las hacen únicas.

Vivimos en un mundo globalizado y en continuo cambio en el que la arquitectura evoluciona a una velocidad vertiginosa, a diario aparecen nuevas ideas de afrontar la construcción, mientras que antes la forma de "hacer» se perpetuaba años y años pasado de padres a hijos el conocimiento. En este caso, la bóveda de Acrobat acompañó a la Ciudad de Cáceres durante cientos de años y ahora corre el riesgo de ser absorbida por los nuevos modelos. La línea entre lo que debemos conservar y lo que no se diluye, por lo que es importante guardar las características de cada cultura, de cada ciudad para evitar que se pierda esa riqueza.

La investigación pretende concretar como las relaciones entre "la forma", "la construcción" y "la estructura" son una unidad indisoluble en un ámbito complejo: la ciudad".

$6 \quad$ En este punto es muy importante señalar los diferentes trabajos de Vicente López Berna Manuel Fortea Luna, Francisco Javier Pizarro Gómez y José Sánchez Leal.

7 (...) Artículo 5. La planificación de la conservación de las poblaciones y áreas urbanas históricas debe ser precedida por estudios multidisciplinares.

El plan de conservación debe comprender un análisis de datos, particularmente arqueológicos, históricos, arquitectónicos, técnicos, sociológicos y económicos, y debe definir la principal orientación y modalidad de las acciones que han de lecise a jurídico, administrativo y financiero. E re el área urbana histórica y el conjunto de la población.

El plan de conservación determinará los edificios o grupos de edificios que deben protegerse totalmente, conservar en ciertas condiciones, o los que, en circunstancias excepcionales, pueden destruirse. Antes de realiza cualquier intervención se levantará un acta, rigurosamente documentada, de las condiciones del área.

El plan debe contar con la adhesión de los habitantes.(...)

Carta Internacional para la Conservación de Poblaciones y Areas Urbanas Históricas (1987). Adoptada por ICOMOS en octubre de 1987 


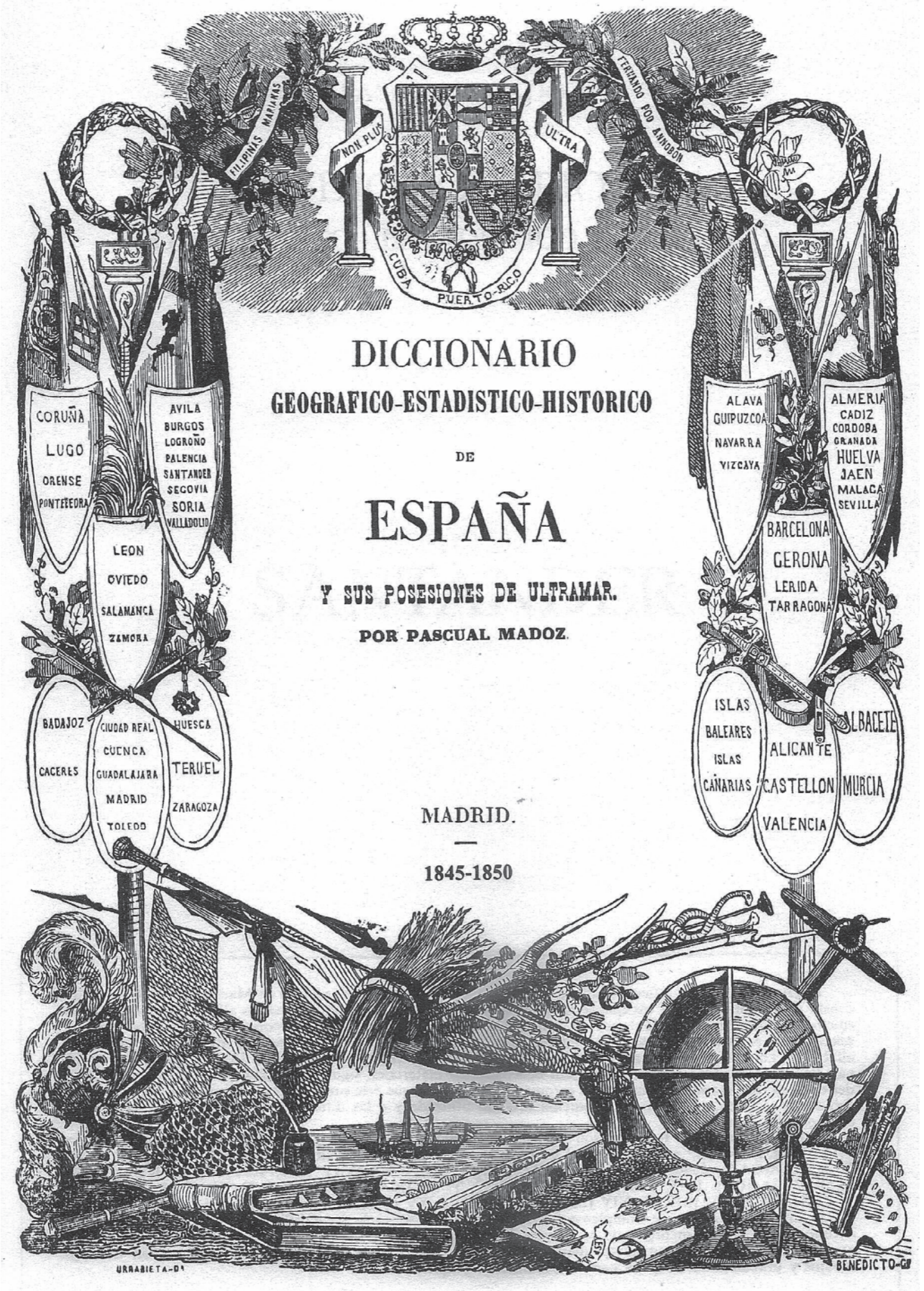

Figura15. Portada del diccionario geográfico-estadístico-Histórico de España y sus posesiones de Ultramar por Pascual Madoz.

\subsection{JUSTIFICACIÓN DEL TEMA}

La ciudad vieja de Cáceres esta marcada por una clara tipología edicatoria. El estudio de esta tipología se aclara conociendo la bibliografía y la Ciudad, porque lo que llama la atención de cualquier visitante, ya ha llamado la atención de diversos autores, como advierte Pascual Madoz:

"Todas estas localidades comprenden 2.115 CASAS de morada, de las cuales son muchas elegantes, de 2 y 3 pisos, con azoteas ó terrados en su parte superior algunas magníficas que harían honor á las mas populosas c. , y todas de sólida construcción con bóvedas en las habitaciones bajas y aun en las principales fuertes columnas de piedra berroqueña en sus buenos patios ; escaleras de piedra labrada y firmes arcos de ladrillo y cal, que remplazan con notable ventaja á las maderas que se acostumbran en otras cap. : sus balcones todos de hierro son espaciosos, y sus fachadas todas lucidas y blanqueadas, ofrecen una agradable perspectiva ; son sin embargo una excepción de esto último, muchos edificios sit. en la parte ant. de la pobl., en los que todavia se advierten las paredes negruzcas y las estrechas ventanas de la dominación sarracena."

O en el caso de los arquitectos Vicente López Bernal y Manuel Fortea Luna:

"Esta región, sobre todo la baja Extremadura, no ha sido rica ni en medios económicos ni materiales, por lo que ha tenido que recurrir a técnicas constructivas que se pudieran desarrollar con lo más asequible a su alcance, y estos eran la tierra y la piedra como materia prima. Con este condicionante la bóveda estaba predestinada a convertirse en uno de los protagonistas más relevantes de cualquier

8 En esta descripción de la Ciudad de Cáceres p.82 (Madoz, 1846) ya se advierte que existe una clara tipologia edificatoria que marca la imagen urbana y compone los edificios, siendo un elemento de gran importancia la bóveda al modular los edificios y por supuesto un elemento que llama la atención del visitante. 


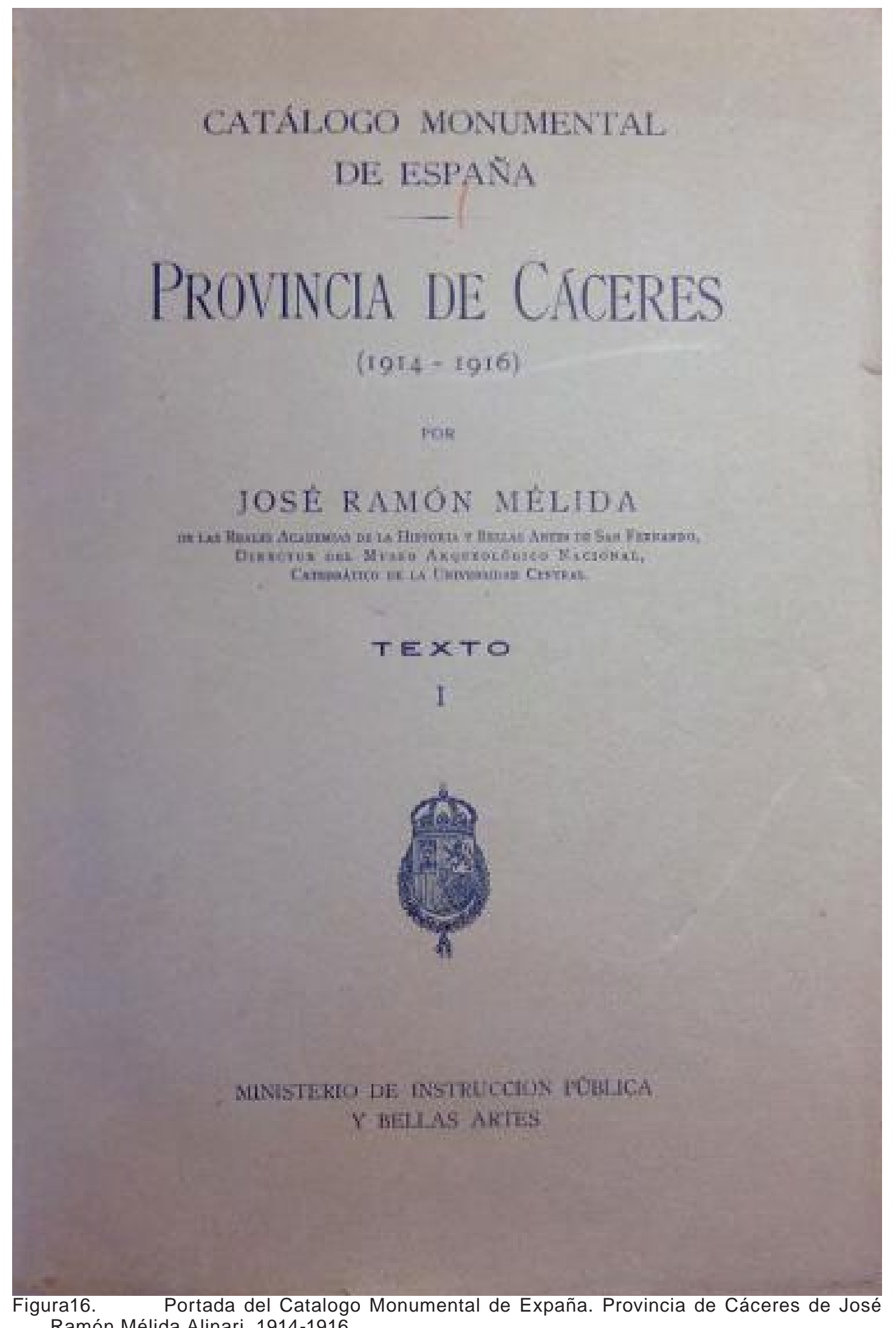

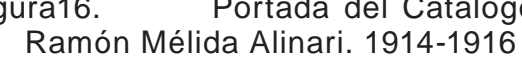

\section{proceso constructivo."}

Con este punto de partida, la alerta por parte de otros autores de en que fijarnos cuando miremos a la Ciudad y a sus edificios se sientan las bases para clasificar y analizar el sistema constructivo que da forma a estos conjuntos edificatorios: "bóvedas ejecutadas a rosca": geometría, tipologías, fábricas...

Toda esta búsqueda de valores, tanto históricos, como arquitectónicos como significativos es el marco conceptual que enmarca el modo de actuación, pero para garantizar este estudio y que tenga una continuidad esta forma de pensar en el tiempo es necesaria la creación de una metodología que nos permita acometer este trabajo, que sea replicable tanto en el tiempo como en el espacio por diferentes personas y que sirva para la integración de datos de diversas fuentes: documentar y conservar.

Así, no solo estamos analizando este sistema constructivo, en realidad estamos definiendo la imagen de la ciudad, estamos viendo como se relacionan los edificios, estamos definiendo un sistema constructivo que no solo es Patrimonio en si mismo ${ }^{10}$ sino que además se transforma en imagen urbana ${ }^{11}$

El método de análisis propuesto para acometer el estudio es a partir de círculos concéntricos, que sirvan para parametrizar la ciudad buscando elementos en común dentro de las edificaciones. De este modo los diferentes estratos o

9 Fortea Luna and López Bernal 1998, p.17, en esta publicación los arquitectos Manuel Fortea Luna y Vicente López Bernal vuelven a remarcar la preponderancia de este sistema constructivo en nuestra región, desarrolando en este libro las peculiaridades de este tipo de bóvedas y sus condicionantes.

10 Como ya he dicho el planteamiento siguiendo la pensamiento de Antonio González Moreno-Navarro y de su equipo es que el Patrimonio no es un objeto en si mismo, si no que también lo componen las técnicas constructivas propias de cada lugar, en las que mas importante que el edificio es el propio sistema constructivo que había dado origen al mismo

11 O en este caso preciso, un sistema único y propio que se da tanto en una gran parte de Extremadura y del Bajo Alentejo, con lo que tambien por extension no es solo Patrimonio de una ciudad sino también de una región. Ver SANCHEZ LEAL, J. 2000. Bóvedas extremeñas y alentejanas de rosca y sin cimbra. Tercer Congreso Nacional de Historia de la Construcción. Sevilla: I. Juan de Herrera, SEdHC, U. Sevilia, Junta de Andalucia, COAAT Granada, CEHOPU 2000. 

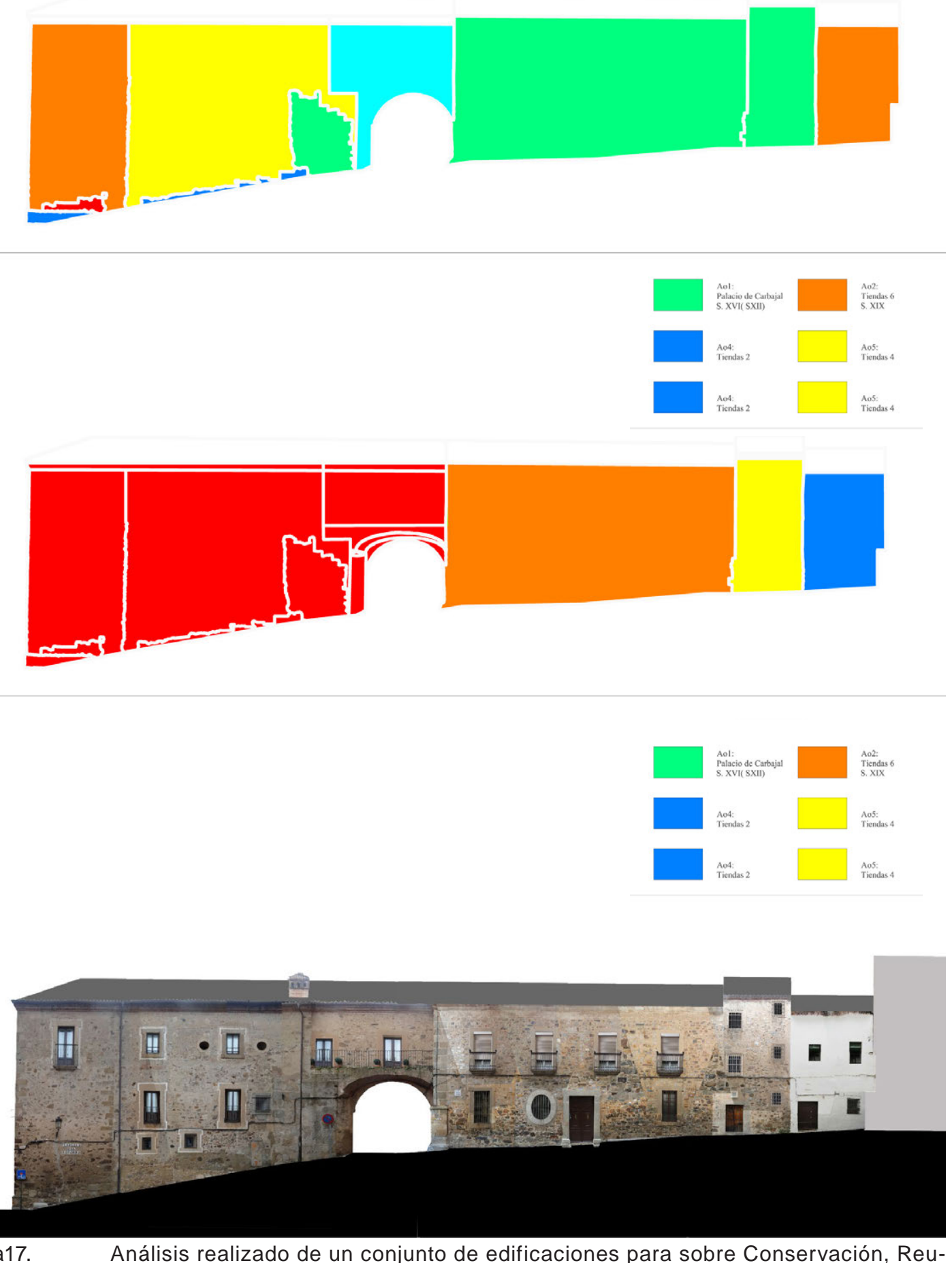

Análisis realizado de un conjunto de edificaciones para sobre Conservación, ReuImagen del autor. CRUZ FRANCO, P. \& RUEDA MÁRQUEZ DE LA PLATA, A. 2013. círculos son capas de información. Estas capas de información son comunes a unos edificios y a otros no. De este modo podemos desechar ciertos elementos que en este trabajo no son útiles, o apartarlos para utilizarlos más tarde o en futuras investigaciones pero siempre haciendo especial hincapié en las relaciones existentes entre unos edificios $u$ otros.

De acuerdo a esto en nuestra metodología de trabajo respecto a círculos concéntricos (o diferentes escalas de aproximación) se justifica la necesidad de contextualizar este elemento constructivo dentro de la ciudad y plantear su puesta en valor a través de los edificios, es un camino de doble sentido, en el que surgen nuevamente otras necesidades relacionados con el aspecto urbano, así: documentar, controlar, administrar y planificar (las intervenciones), es el resultado inevitable de estudiar un sistema constructivo como imagen urbana de la ciudad (e incluso del territorio)

De acuerdo a esta escala de aproximación se han realizado levantamientos de los edificios utilizando diferentes sistemas de acuerdo a la escala, que condiciona el modo de afrontar la realidad y que buscan en último extremo:

- Valorar el territorio, la ciudad y por último los edificios como contenedores de elementos significativos. Ver el conjunto como un sistema que se interrelaciona.

- Mejorar de la calidad paisajística de la zona a través del conocimiento de la misma.

- Hacer entrar en valor los pequeños elementos( en nuestro caso las bóvedas de rosca) dentro de la ciudad como si de celdas que forman parte de una cuadrícula se tratara y (Sánchez Leal, 2000) esto extrapolarlo en última instancia al territorio: conocimiento y divulgación.

Así, este estudio tiene una dualidad, por un lado está la investigación realizada que tiene que ser un elemento crítico, una base de conocimiento que nos ayude a documentar y comprender la ciudad y a través de este conocimiento, capacitar y desarrollar una arquitectura específica, con unos valores específicos, para afrontar 


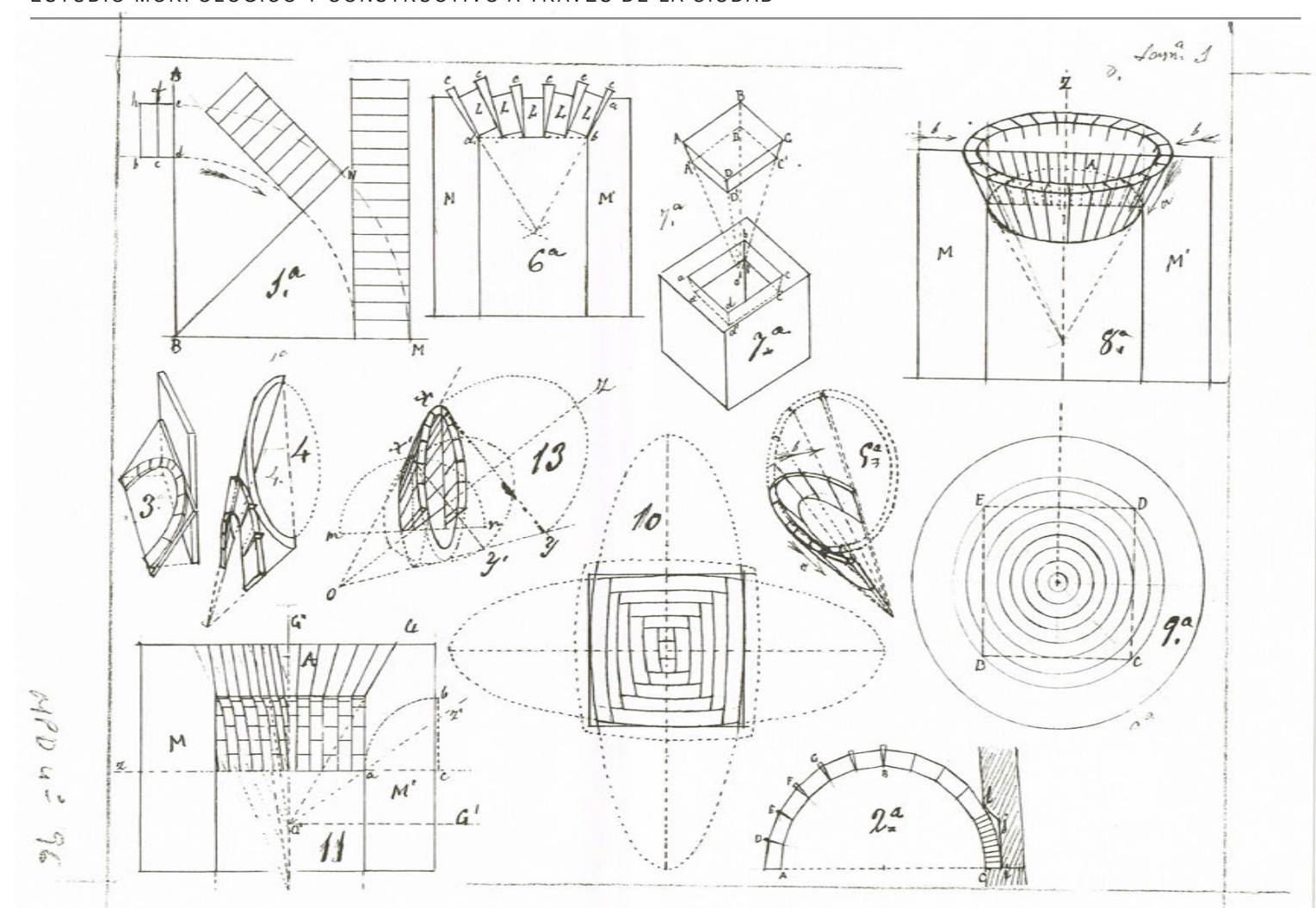

Figura18. Lámina 1 extraída del tratado de bóvedas sin cimbra de Vicente Paredes Guillen. Pi-

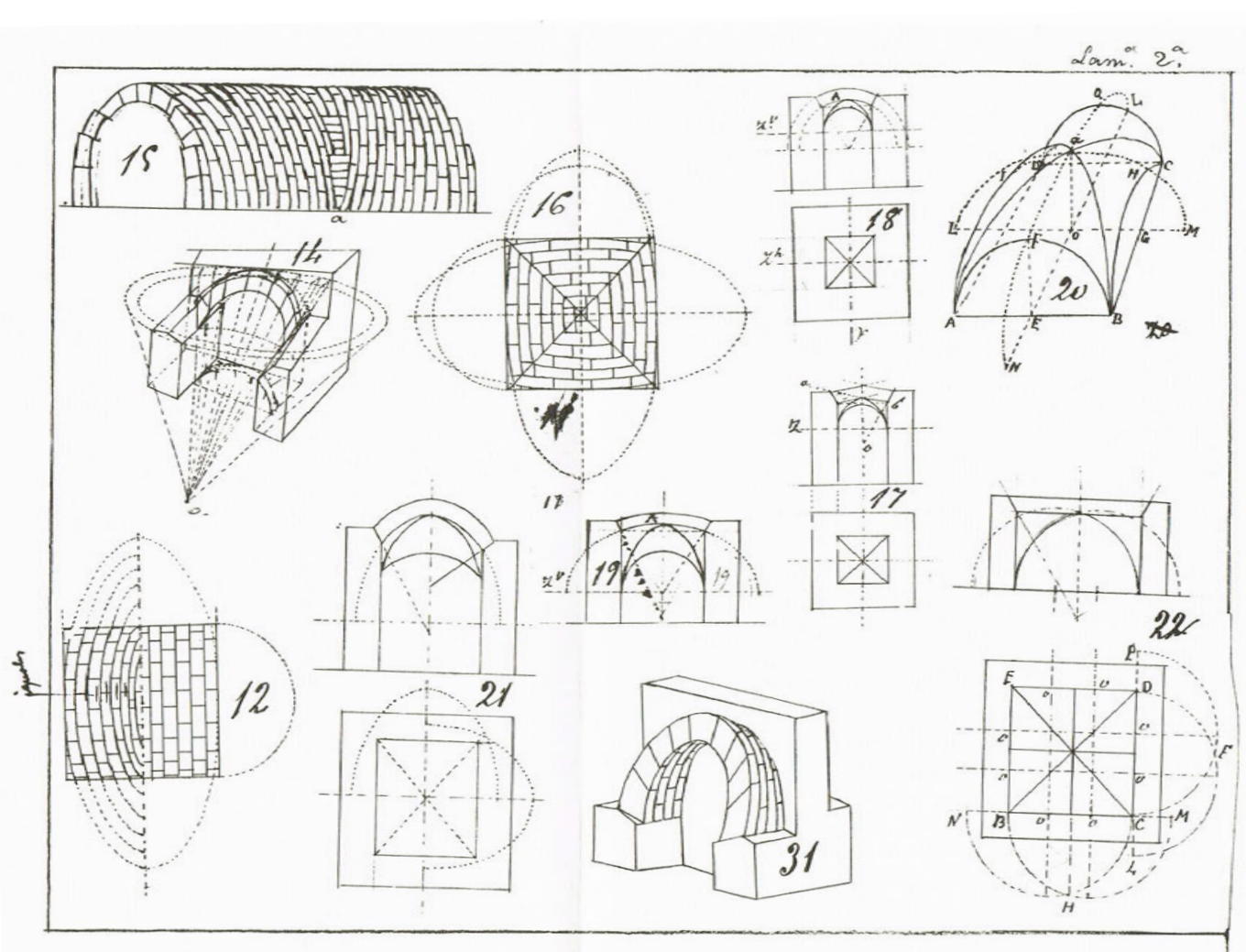

Figura19. Lámina 2 extraída del tratado de bóvedas sin cimbra de Vicente Paredes Guillen. PiGuillén. Estudio y transcripción: Consejería de Fomento de la Junta de Extremadura. como ya he recalcado desde el territorio ${ }^{12}$, la ciudad ${ }^{13}$ y por último el edificio: en definitiva la necesidad de conservar.

Y junto a esta conservación, de forma indisoluble, aparece el proyecto que será el encargado de la preservación de la calidad del espacio y de las características específicas del lugar, aunque para esto en muchas casos sea necesaria una concienciación de los usuarios.

\section{Artículo publicado en el periódico HOY el 09/03/09, "Cientos de ellas en la raya"}

Sobre bóvedas hay extensos tratados que sólo los especialistas y albañiles como Máximo Porta devoran con los ojos y un lápiz al lado. «La bóveda autosostenida extremeña es fruto de los condicionantes geomónicos y climálicos de esta region. La falta de madera, la buena calidad de las cales extremeñas, y las condiciones climáticas condicionaron el desarrollo de bovedas en las que no hace falta el concurso de la madera para su construcción (cimbras) y que garanticen unas buenas condiciones de habitabiliad y ahorro energeticos, prologaba en 2004 el entonces director genera de Urbanismo, Arquitectura y Ordenación del Territorio de la Junta de Extremadura, Víctor Zarco, en una edición de lujo del tratado del cacereño Vicente Paredes Guillén (1840-1916), que recogio en un manuscrito inacabado las reglas de lo que se dio en llamar Bóveda extremeña.

13 "Cáceres- que se aproxima hoy a los cincuenta mil habitantes-es, sin duda alguna, uno de los conjuntos monumentales más completos de España y del mundo. Su interés fundamental radica precisamente en esto. el visitante no encuentra aqui el monumento de primer orden aislado, perdido entre calles y edifios sin personalidad ni sabor, sino un mundo que se paro hace siglos; un pueblo en el que los granicos palacios y las iglesias graniticas, las murallas y las torres, las callejuelas y las plazas, tejen una arquitectonica sinfonia impresionante. No hay catedral grandiosa, ni monumento excepcional, sino el conjunto único y maravilioso, de una ciudad que perdió la noción del tiempo, para quedar aislada a un pasado evocador e ilustre."

Reflexión de don Miguel Muñoz de San Pedro, en su estudio histórico artístico de la ciudad de Cáceres (Muñoz de San Pedro e Higuero, 1954) p. XIII 


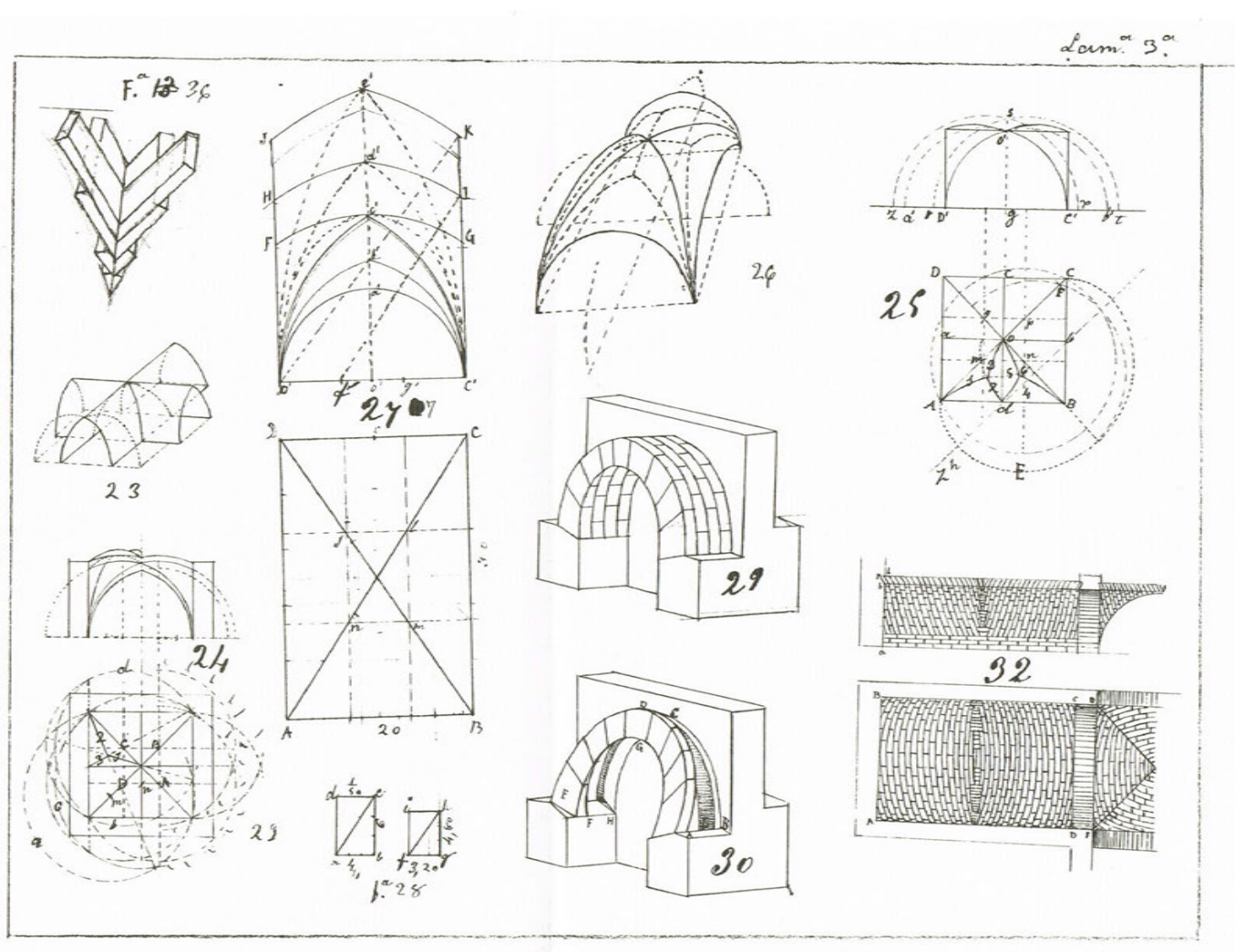
Figura20. Lámina 3 extraída del tratado de bóvedas sin cimbra de Vicente Paredes Guillen. Pi-
zarro Gómez, F. J., \& Sánchez Leal, J. (2004). Tratado de bóvedas sin cimbra de Vicente Paredes Guiltén. Estudio y transcripción: Consejerín de Fomento de la Junta de Extremadura.

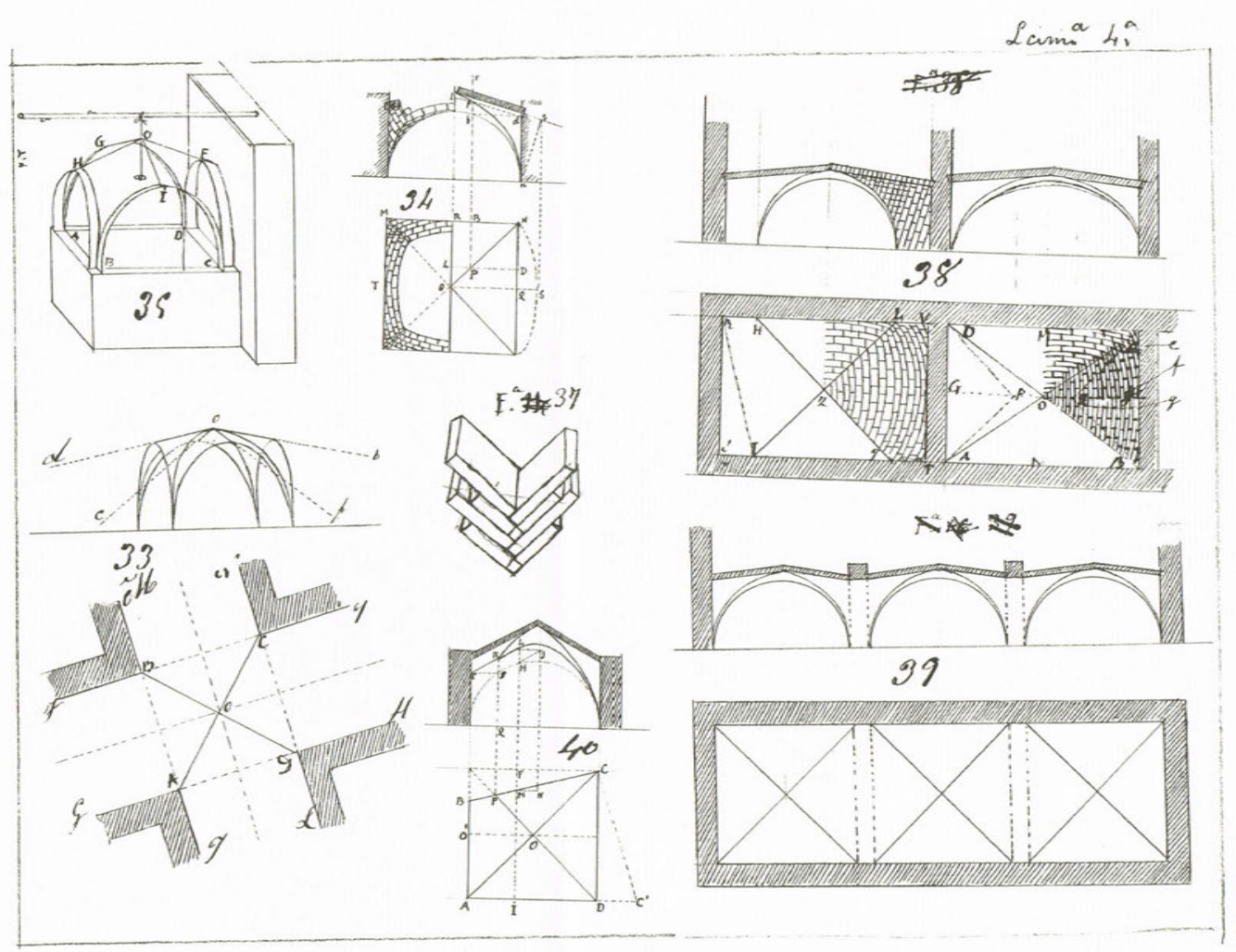

Figura21. Lámina 4 extraída del tratado de bóvedas sin cimbra de Vicente Paredes Guillen. PiGuillén. Estudio y transcripción: Consejería de Fomento de la Junta de Extremadura.

\subsection{ESTADO DEL ARTE}

Es en este punto, donde esta tesis comienza a cobrar sentido. La primera pregunta que debe surgir al comenzar este estudio, es que diferencia a estas bóvedas, que llamamos de "rosca" ${ }^{14 "}$ del resto de bóvedas que pueblan España Que es lo que las hace diferentes y por que los distintos autores que hablan de ellas se empeñan en diferenciarlas de otras.

Esta diferencia, la particularidad que crea la necesidad de catalogarlas, de distinguirlas de otras y de estudiarlas a parte, es su modo de ejecución fuera de lo común, es decir como los artesanos las hicieron y las siguen haciendo, "al aire"15, es decir sin ayuda de cimbra.

Este hecho, que supone un clara ventaja económica ${ }^{16}$, no es fruto de la casualidad, lo que a nuestros ojos se presenta como una bóveda común no lo es y no es fruto únicamente de la habilidad del artesano que la ejecuta. Como veremos a continuación, siguiendo los trabajos de otros autores para asentar las bases de tema, es el resultado de sutiles variaciones en la forma, la geometría y el aparejo

14 Al leer sobre este tema se encuentran diferentes denominaciones para designar a este elemento constructivo, unos las llaman "bóvedas de rosca", otros "bóvedas autosostenidas", otros "bóvedas ejecutadas a rosca" o "bóvedas extremeñas". Todas estas designaciones válidas y todas

15 Esta ejecución al aire como es bien sabido, no solo es propia de la región de Extremadura, e

16 Este hecho es especialmente importante, por un lado supone un cuantioso ahorro económico a la hora de ejecutarlas como ya señalan los arquitectos Manuel Fortea Luna y Vicente Lopez Bernal en su obra Bóvedas de ladinlo proceso constructivo y análisis estructural de bóvedas de arista, puesto que la cimbra como medio de ayuda a la ejecucion de la boveda supone un gasto desproporcionado frente al total del coste de la ejecución del elemento constructivo completo, cercano a $40 \%$, siendo siempre esta cimbra un elemeno que vamos a desechar "

Cada arco toral le han de hacer por cincuenta ducados y pondrán la madera a su costa de las cimbras y si su Excelencia diera las cimbras hechas harán cada arco por treinta ducados..." ARCHIVO HISTORICO DE PROTOCOLOS DE MADRID, escribania de Francisco Testa, legajo 2621, ff. 574 vo. a 582 ro. Escritura de condiciones iglesia de Santa Marina..., Cit. en MANUEL FORTEA LUNA. VICENTE LOPEZ BERNAL. Bóvedas extremeñas. Proceso constructivo y analisis estructual de bovedas de arista. 1998. p 26. 


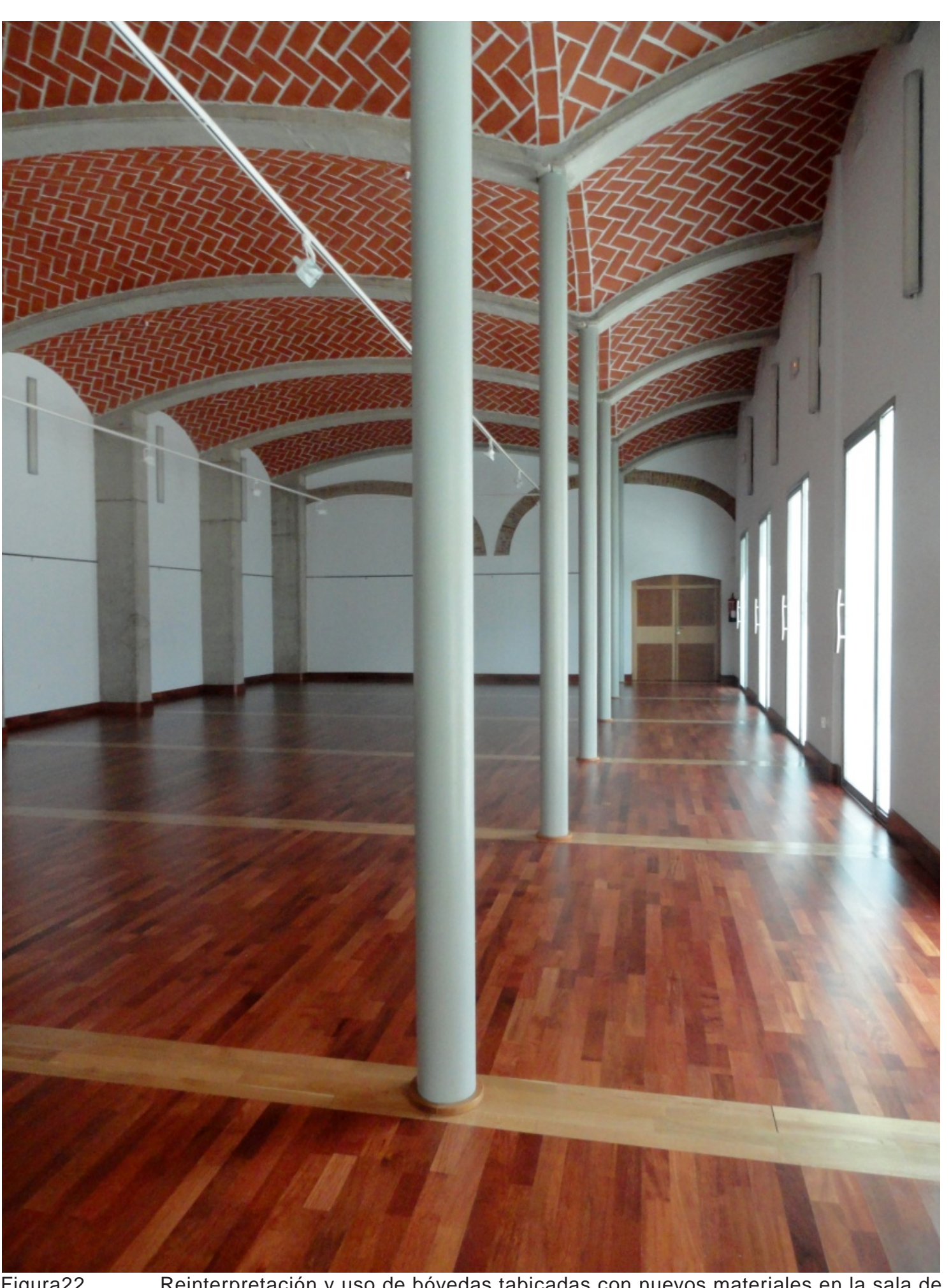

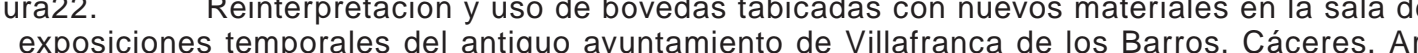
quitecto: Vicente López Bernal.
Esta particularidad, la de ser ejecutada sin ayuda de cimbra, no es propia unicamente de Extremadura, aunque si que es cierto que no es común. En nuestra geografía se encuentra otro caso igual de llamativo, las bóvedas tabicadas ${ }^{17}$, que se desarrollan con especial énfasis en las regiones de Cataluña y Valencia ${ }^{18}$, donde se transforman en seña de identidad de una arquitectura que las usa con especial habilidad, inciandose con tempranas referencias, entre ellas uno de los primeros ejemplos es la de la capilla Real del Rey Martin el Humano en la Catedral de Barcelona, realizada en el año 1407 (siglo XV) ${ }^{19}$. O en ese mismo año, Truñó nos indica nos referencia el claustro del hospital de la Santa Cruz de Barcelona en el que se encuentra esta tipología de bóvedas, destacando de ellas el rebaje de las mismas.

Así, este sistema se vuelve en primer lugar particular por su construcción sin la ayuda de cimbras ni elementos auxiliares y es en la figura del arquitecto

17 "Generalmente se denomina bóveda tabicada a la realizada mediante la superposición de por lo menos dos capas de rasillas puestas con la tabla tangente a la directriz de la bóveda; la primera hoja conforma el intradós; la segunda y las hojas sucesivas, si las hay, se colocan sobre baño de mortero a rompe-juntas sobre las anteriores. El apelativo de tabicada ya aparece en textos del siglo XVII y hace referencia a su semejanza, en su delgadez y modo de realización, con el tabique de panderete, que también se construye con los ladrillos puestos de tabla. "José Luis González Moprén tabicadas, Ángel Truño, (Truñó, 2004) p. X

18 De origen incierto, probablemente romano. Encontramos los primeros ejemplos inicios de siglo XV. Y ha llegado a perdurar hasta los años 80 del siglo XX, con sobresalientes ejemplos en la arquitectura Calalana que la transtorma en estandante de su culura a traves de maestros como es Antoni Gaudi, quien con las domina demostrando su conocimiento de la geometria y la mecánica. Por otro lado tambien destacar su uso en los pueblos de colonización, esa arquitectura de la postguerra que en una racionalización de los medios y la naturaliza de cada región edifica esas nuevos pueblos fusionando tradición, historia y economía de medios, para dar lugar a una arquitectura rural

19 Destacada ese percepción de la bóveda tabicada como elemento resistente, que es necesario ocultar por un falso techo plano de yeso, quizas porque no transmite para el artesano esa calidad constructiva que otros sistemas proyectaban al espectador de la época. (Bassegoda, 1997) 


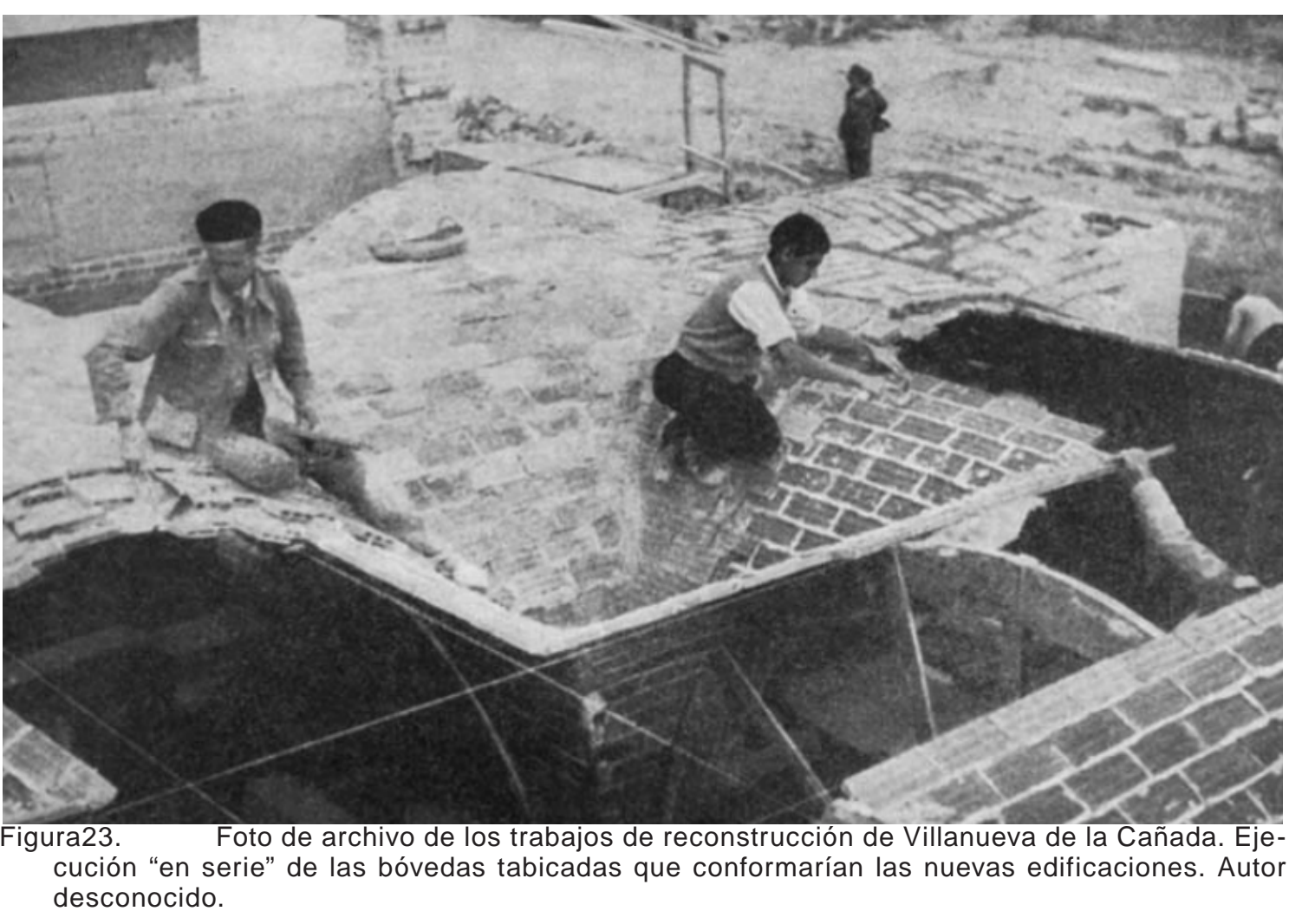
cución "en serie"
desconocido.

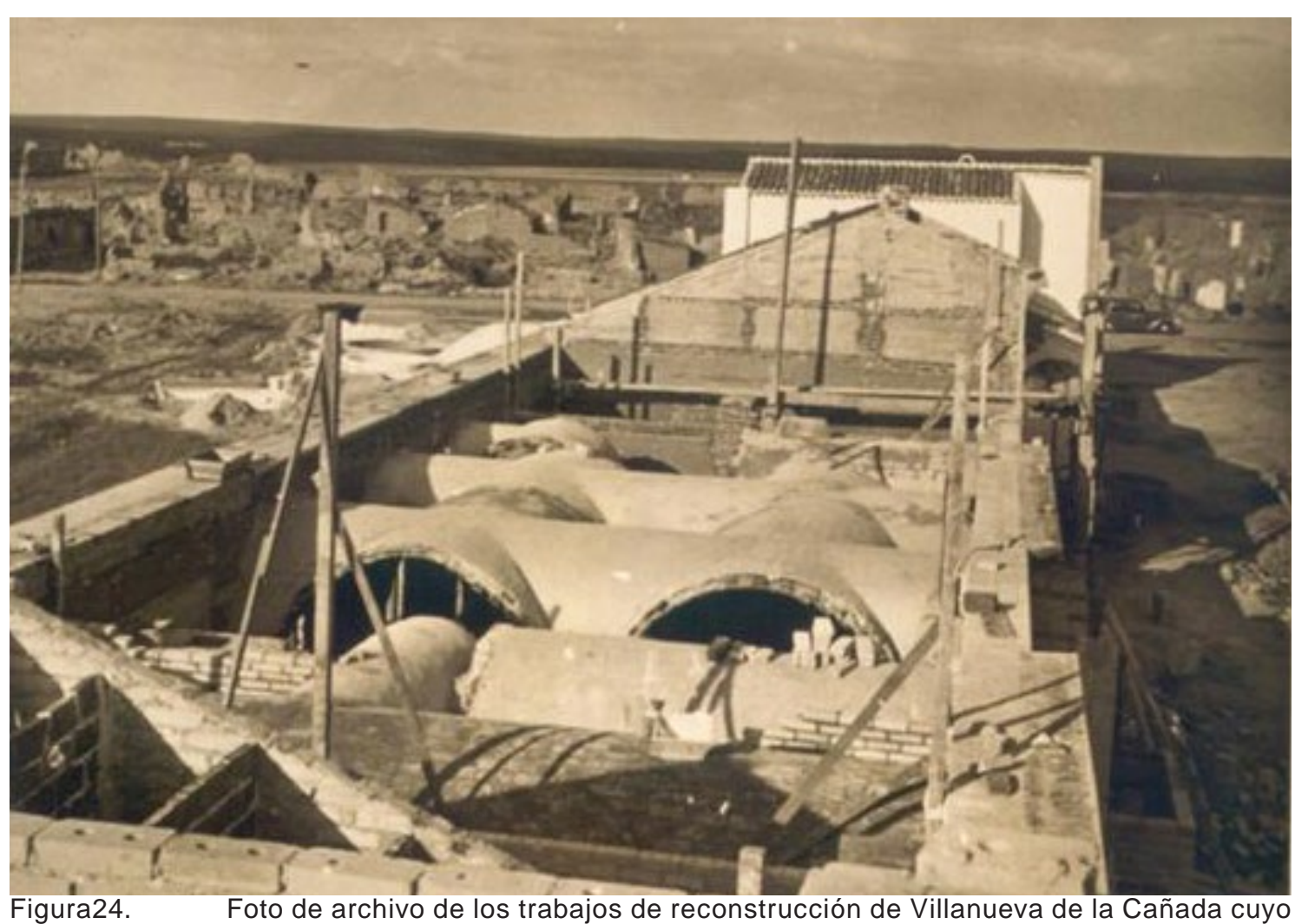
Figura24. Foto de archivo de los trabajos de reconstrucción de Villanueva de la Cañada cuyo
proyecto de reconstrucción fue desarrollado por los arquitectos Manuel Moreno de la Casa,
Juan Castañón y Alfonso Fungairiño
Vicente Paredes Guillén (1840-1916) ${ }^{20}$ en primer lugar y en segundo lugar de los arquitectos Manuel Fortea Luna y Vicente López Bernal, donde este documento encuentra sus cimientos para iniciar el estudio.

De este modo Según Vicente Paredes Guillen para construir estas bóvedas sin cimbra tendríamos pues dos alternativas: la primera mediante la elección de morteros ${ }^{21}$ extremademente fuertes que vuelvan solidarias las fábricas unas con otras ${ }^{22}$. En segundo lugar a disminución del tamaño de "las piezas agentes" hasta que el mortero pueda sostenerlas.

Por otro lado en su tratado señala la importancia de la geometría: "Las bóvedas de ladrillo que generalmente se hacen sin cimbra son aquellas que se componen de hiladas cerradas ${ }^{23}$ y son partes de un solo cuerpo geométrico, tales

20 Francisco Javier Pizarro Gómez y José Sánchez Leal transcriben y se estudian el trabajo de este arquitecto en su Tratado de bovedas sin cimbra. (Pizarro y Sanchez, 2004)

21 Citando a Vicente Paredes Guillén estos morteros de extremada fortaleza tienen la misión de transformar las "piezas agentes" en "piezas pacientes" al unirlas. Siendo estos agentes y estos pacientes:

Cuando la pieza es paciente, únicamente es necesario colocar las piezas en su debido orden, correctamente. Cada pieza permanece en su lugar únicamente colocándola en él.

Cuando la pieza es agente necesita para permanecer en su lugar que actúen DOS fuerzas de las partes pacientes para mantenerse en su lugar y esto no es posible hasta que la estructura está concluida.

Paciente provisional, durante la construcción aporta estas dos fuerzas que necesitan los agentes para mantenerse estable y más tarde cuando la estructura esté concluida poder retirarse. En el caso de las bóvedas la cimbra.

22 La función del mortero es conglomerar estas fábricas como si fuesen una sola, consiguiendo "las dos fuerzas necesarias para mantenerse estable y de esta forma evitar al "paciente auxilia".

23 De acuerdo a Vicente Paredes en el Estudio y trascripción del Tratado de bóvedas sin cimbra a de Vicente Paredes Guillen (Pizarro y Sánchez, 2004) para que la hilada se cierre no es preciso que se cierre sobre si misma, hay muchos modos, unicamente las piezas deben quedar inmoviles, unicamente la parte de cierre debe resistir el empuje que hacen las piezas hacia el centro de su vuelta o hacia el punto o línea en la que converjen los lechos. 
como el cono, la esfera y el elipsoide" 24 ejecutadas todas con hiladas con lechos y sobrelechos cónicos e hiladas cerradas por si mismas siendo para Vicente Parede los conos constructivos, instrumento en la construcción sin cimbra de las bóvedas.

En último lugar, serán los arquitectos Manolo Fortea Luna y Vicente López Bernal ${ }^{25}$, quienes definan el marco teórico de este singular sistema constructivo, aparentemente una bóveda de arista tradicional pero que en realidad es el resultado de años de historia que se entrelazan para dar lugar a una forma de construir con particularidades morfológicas, constructivas y estructurales que se describen en el capítulo 2, apartado 2.1 la bóveda de rosca.

Por otro lado las bóvedas de rosca han sido analizadas con gran acierto

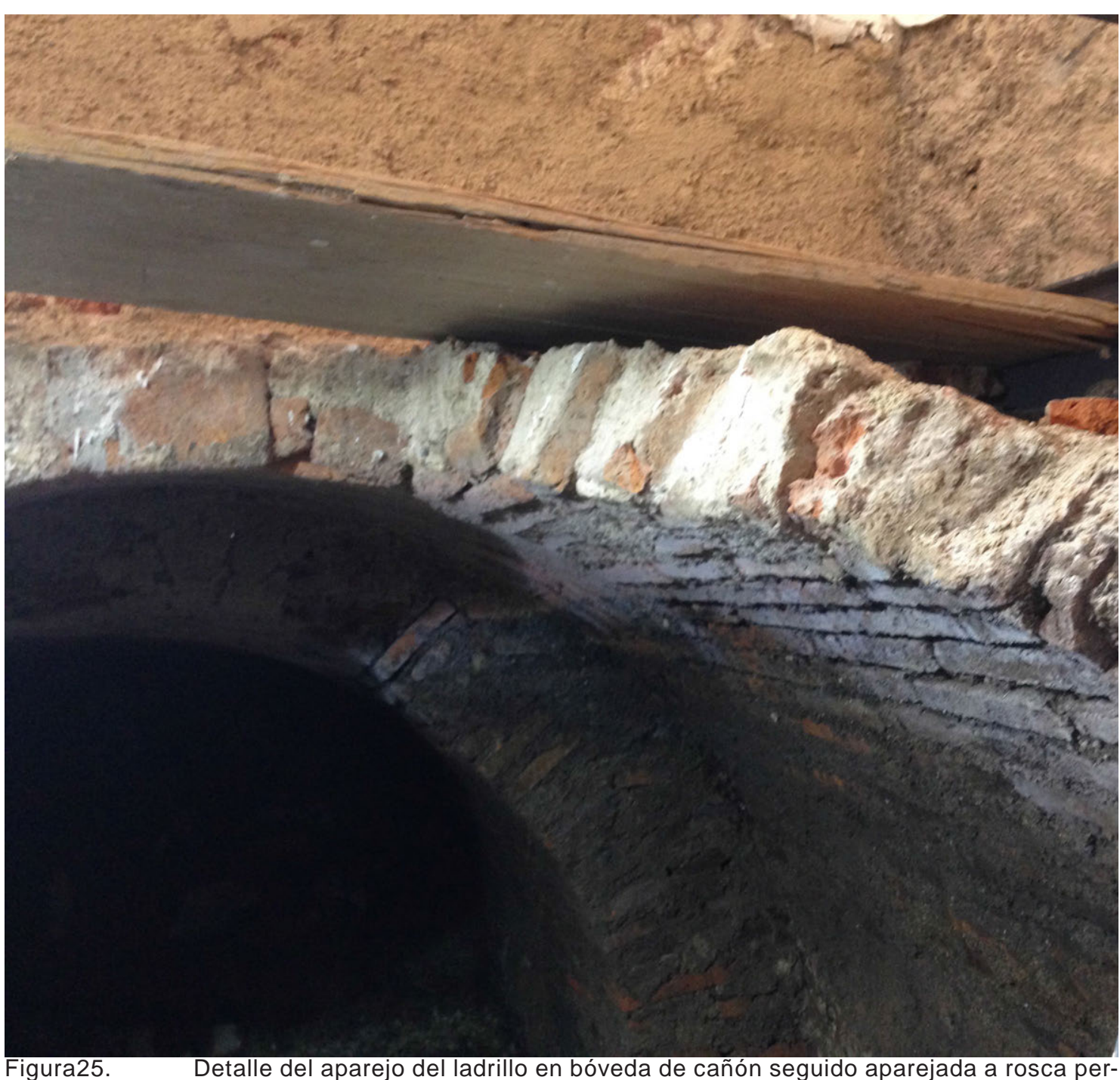

ters. Detalle del aparejo del ladrillo en bóveda de cañón segr teneciente a cisterna para captación de agua loca
Cruz\&Rueda Arquitectos. Imagen del autor 2015. existentes grandes ejemplos de cómo abordar su restauración o de cómo dar continuidad a un sistema constructivo tradicional, siendo quizás el ejemplo más impactante, las bóvedas del refectorio de San Benito de Alcántara de Dionisio Hernández Gil.

A pesar de todas las aportaciones de autores sobre este tema, la percepción de este sistema constructivo en la actualidad, es fuera de algunos círculos, sesgada y en algunos casos "floklorico". La visión de la bóveda de rosca, fuera de estos ámbitos más intelectuales, es la de un elemento aislado dentro del patrimonio histórico-artístico es inadecuada y puede generar actuaciones ineficaces que no responden correctamente a las específicas características formales, materiales y tecnológicas de esta arquitectura tradicional.

24 Bóveda esférica: engendrada por dos semicircunferencias, con eje vertical común. Aparece el concepto de hiladas anulares y cónicas. Bóvedas cónicas: las hiladas serán cónicas y tendrán sus vértices en el eje de la boveda. Bovedas ellpicas. los conos, a que son adaptables sus lechos y sus sobrelechos, tienen una elipse por sección recta, son igualmente cerradas.

25 Entre otros trabajos destacar el libro Bóvedas de Ladrillo. Proceso constructivo y análisis estructural de bovedas de arista (Fortea y Bernal, 1998) u otras publicaciones como son Analisis estructural de bovedas de fabrica. La eficacia de la geometría (Fortea, 2013), La magia estructura de la boveda tabicada (Fortea, 2009) o Origen de la bóveda tabicada (Fortea, 2009). 

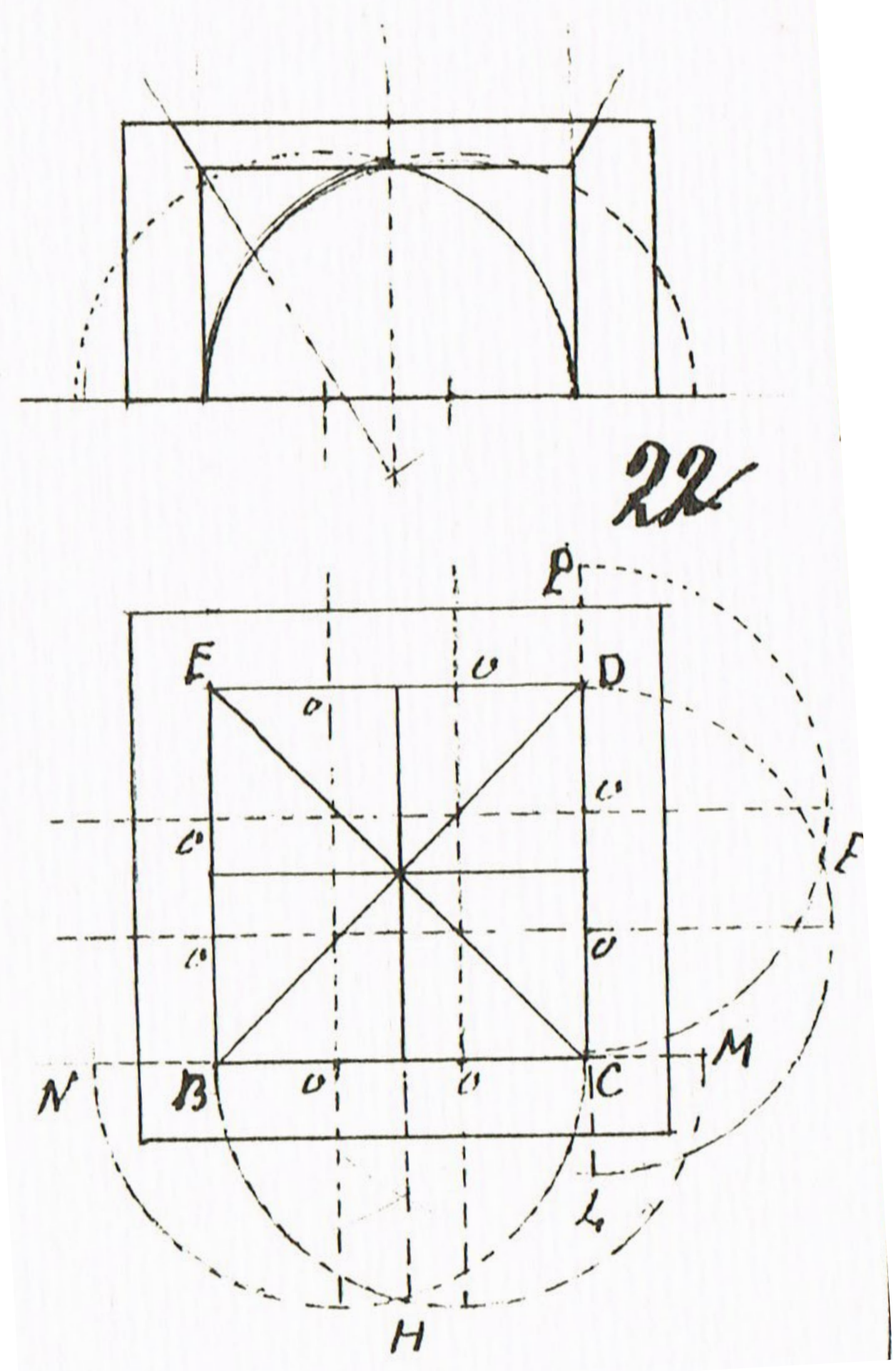

Figura26. Detalle perteneciente a la Lámina 2 extraída del tratado de bóvedas sin cimbra de Vicente Paredes Guillen. Pizarro Gómez, F. J., \& Sánchez Estudio y transcripción: Consejería de Fomento de la Junta de Extremadura.
Concretamente dentro de la ciudad de Cáceres, existe el grave riesgo de que este conjunto inalterado a lo largo de los siglos caiga en una arquitectura de fachadas al perderse la visión de global. Generándose a consecuencia de ello, un amplio tejido de graves y dañinas actuaciones que la están mutilando y que en un futuro próximo pueden hacerla desaparecer.

Para finalizar, al tratar un tema de este tipo, es inevitable no hacer referencia a los grandes teóricos y críticos de la restauración: Camillo Boito(1836-1914) por su capacidad de aplicar distintas soluciones al problema de la restauración dependiendo del edificio a tratar; Gustavo Giovanoni(1873-1947), que promueve las obras de consolidación y mantenimiento, a través del uso de técnicas modernas, sin perder de vista el respeto a todas las partes; Cesare Brandi(1906-1988), por su lucha por mantener el equilibrio entre la teoría de la restauración, la conservación y la práctica de la restauración con carácter multidisciplinar; o por último Guido Canalli(1934), con su restauro crítico. 